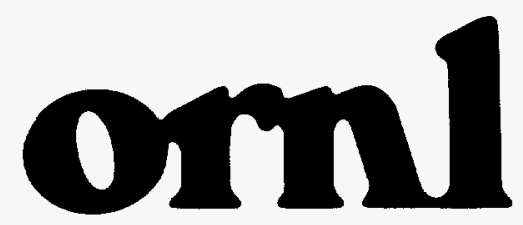

CAK PIDCE NATCONA LABORANORY

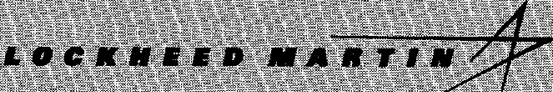

\section{}

MWGED AMO OPERITEO BY

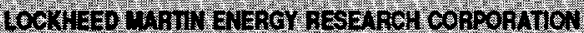
FOR THE UITEO STATES

DEPARTIET OF EHERGY
RECEIVED

$$
\begin{array}{r}
\text { FFA O } 5998 \\
\text { OSTI }
\end{array}
$$

\section{ENERGY DIVISION}

\section{ANCILLARY SERVICE DETAILS: VOLTAGE CONTROL}

Brendan Kirby

Eric Hirst

MASTER 
This report has been reproduced directly from the best available copy.

Available to DOE and DOE contractors from the Office of Scientific and Technical information, P.O. Box 62, Oak Ridge, TN 37831; prices available from (423) 576-8401, FTS 626-8401.

Available to the public from the National Technical Information Service, U.S. Department of Commerce, 5285 Port Royal Rd., Springfield, VA 22161.

This report was prepared as an account of work sponsored by an agency of the United States Government. Neither the United States Government nor any agency thereof, nor any of their employees, makes any warranty, express or implied, or assumes any legal liability or responsibility for the accuracy, completeness, or usefulness of any information, apparatus, product, or process disclosed, or represents that its use would not intringe privately owned rights. Reference herein to any specilic commercial product, process, or service by trade name, trademark, manufacturer, or otherwise, does not necessarily constitute or imply its endorsement, recommendation, or favoring by the United States Government or any agency thereof. The views and opinions of authors expressed herein do not necessarily state or reflect those of the United States Government or any agency thereof. 


\section{DISCLAIMER}

Portions of this document may be illegible electronic image products. Images are produced from the best available original document. 
ENERGY DIVISION

\title{
ANCILLARY SERVICE DETAILS: VOLTAGE CONTROL
}

\author{
BRENDAN KIRBY and ERIC HIRST
}

December 1997

Sponsored by

The National Regulatory Research Institute

Columbus, Ohio

OAK RIDGE NATIONAL LABORATORY

Oak Ridge, Tennessee 37831

managed by

LOCKHEED MARTIN ENERGY RESEARCH CORPORATION

for the

U.S. DEPARTMENT OF ENERGY

under contract No. DE-AC05-96OR22464 



\section{CONTENTS}

Page

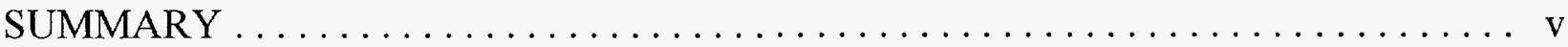

LIST OF ACRONYMS $\ldots \ldots \ldots \ldots \ldots \ldots \ldots \ldots \ldots \ldots \ldots \ldots \ldots \ldots \ldots \ldots \ldots \ldots$

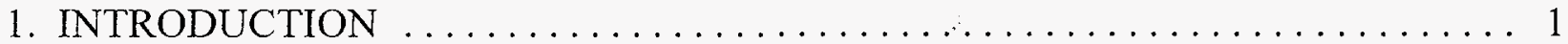

2. TRANSMISSION-SYSTEM VOLTAGE CONTROL $\ldots \ldots \ldots \ldots \ldots \ldots \ldots \ldots$

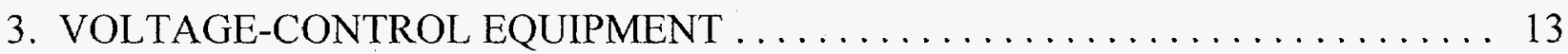

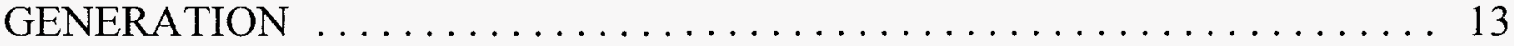

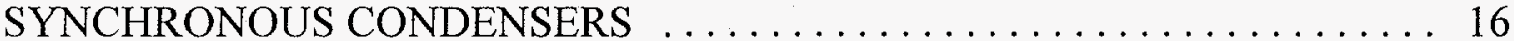

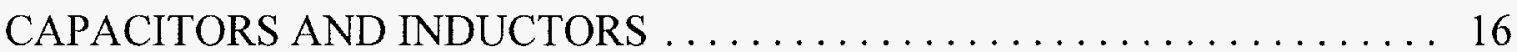

STATIC VAR COMPENSATORS (SVCs) $\ldots \ldots \ldots \ldots \ldots \ldots \ldots \ldots \ldots . \ldots \ldots$

STATIC SYNCHRONOUS COMPENSATORS (STATCOMs) $\ldots \ldots \ldots \ldots \ldots 17$

DISTRIBUTED GENERATION $\ldots \ldots \ldots \ldots \ldots \ldots \ldots \ldots \ldots \ldots \ldots \ldots \ldots$

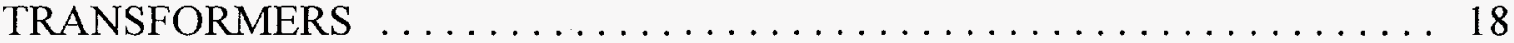

DIFFERENCES AMONG EQUIPMENT TYPES $\ldots \ldots \ldots \ldots \ldots \ldots \ldots \ldots 20$

4. RESOURCE CONTROL AND MARKET STRUCTURES $\ldots \ldots \ldots \ldots \ldots \ldots .21$

TECHNICAL GUIDANCE AND COMPENSATION RULES $\ldots \ldots \ldots \ldots \ldots 21$

REQUIREMENTS IN A RESTRUCTURED INDUSTRY $\ldots \ldots \ldots \ldots \ldots \ldots 23$

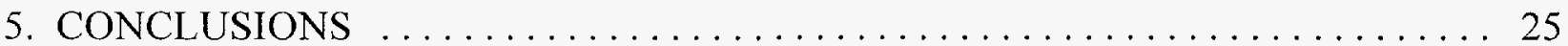

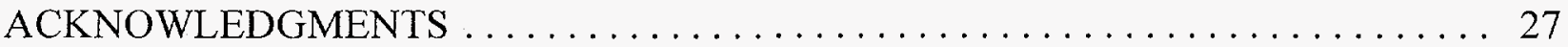

REFERENCES .................................... 29

APPENDIX: REACTIVE-POWER BASICS $\ldots \ldots \ldots \ldots \ldots \ldots \ldots \ldots \ldots \ldots \ldots$ 



\section{SUMMARY}

Voltage control is accomplished by managing reactive power on an alternating-current power system. Reactive power can be produced and absorbed by both generation and transmission equipment. Reactive-power devices differ substantially in the magnitude and speed of response and in their capital costs.

System operators, transmission owners, generators, customers, power marketers, and government regulators need to pay close attention to voltage control as they restructure the U.S. electricity industry. Voltage control can affect reliability and commerce in three ways:

- Voltages must be maintained within an acceptable range for both customer and powersystem equipment to function properly.

- The movement of reactive power consumes transmission resources, which limits the ability to move real power and worsens congestion.

- The movement of reactive power results in real-power losses.

When generators are required to supply excessive amounts of reactive power, their realpower production must be curtailed. These opportunity costs are not currently compensated for in most regions. Current tariffs are based on embedded costs. These embedded-cost tariffs average about $\$ 0.51 / \mathrm{MWh}$, equivalent to $\$ 1.5$ billion annually for the United States as a whole. Although this cost is low when compared with the cost of energy, it still aggregates to a significant amount of money.

This report takes a basic look at why the power system requires reactive power (an appendix explains the fundamentals of real and reactive power). The report then examines the various types of generation and transmission resources used to supply reactive power and to control voltage. Finally it discusses how these resources are deployed and paid for in several reliability regions around the country.

As the U.S. electricity industry is restructured, the generation, transmission, and systemcontrol equipment and functions that maintain voltages within the appropriate ranges are being deintegrated. These changes in industry structure require new institutional rules and markets to plan for additional voltage-support capacity, to reserve that capacity for future use, and to deploy that capacity in real time to meet current and contingency conditions. These services can be obtained through engineering mandates or through markets. Whether the location-specific nature of voltage control will permit the creation of competitive markets is not yet known. 


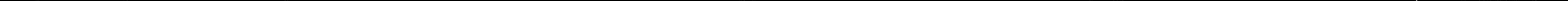




\section{LIST OF ACRONYMS}

AC Alternating current

ECAR East Central Area Reliability Council

FACTS Flexible AC transmission system

FERC U.S. Federal Energy Regulatory Commission

ISO Independent system operator

LTC Load-tap changer

MAIN Mid-America Intrerconnected Network

NEPOOL New England Power Pool

NERC North American Electric Reliability Council

NPCC Northeast Power Coordinating Council

PF Power factor

PJM Pennsylvania-New Jersey-Maryland Interconnection

PU Per unit

SERC Southeastern Electric Reliability Council

SPP Southwest Power Pool

STATCOM Static synchronous compensator

SVC Static VAR compensator 


\section{INTRODUCTION}

Voltage control and reactive-power management are two aspects of a single activity that both supports reliability and facilitates commercial transactions across transmission networks. The Federal Energy Regulatory Commission (FERC 1996, 1997a) recognized the importance of voltage control by including it as an ancillary service in Order 888, Reactive Supply and Voltage Control from Generation Sources. FERC differentiated generation-based activities from transmission-system-based activities, with the latter to be addressed under the basic transmission tariff. In this report we examine both transmission and generator provision of the service to gain a fuller understanding of the overall situation.

On an alternating-current $(\mathrm{AC})$ power system, voltage is controlled by managing production and absorption of reactive power. There are three reasons why it is necessary to manage reactive power and control voltage. ${ }^{*}$ First, both customer and power-system equipment are designed to operate within a range of voltages, usually within $\pm 5 \%$ of the nominal voltage. At low voltages, many types of equipment perform poorly; light bulbs provide less illumination, induction motors can overheat and be damaged, and some electronic equipment will not operate at all. High voltages can damage equipment and shorten their lifetimes.

Second, reactive power consumes transmission and generation resources. To maximize the amount of real power that can be transferred across a congested transmission interface, reactive-power flows must be minimized. Similarly, reactive-power production can limit a generator's real-power capability.

Third, moving reactive power on the transmission system incurs real-power losses. Both capacity and energy must be supplied to replace these losses.

Voltage control is complicated by two additional factors. First, the transmission system itself is a nonlinear consumer of reactive power, depending on system loading. At very light loading the system generates reactive power that must be absorbed, while at heavy loading the system consumes a large amount of reactive power that must be replaced. The system's reactive-power requirements also depend on the generation and transmission configuration.

"Because voltage control and reactive-power management is a mouthful, we refer to this service as voltage control in this report. The Appendix discusses the physics of real and reactive power.

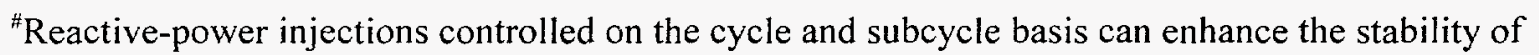
the power system if they are employed in the correct location. This benefit would be covered under the power-system-stability ancillary service rather than voltage control. 
Consequently, system reactive requirements vary in time as load levels and load and generation patterns change.

Second, the bulk-power system is composed of many pieces of equipment, any one of which can fail at any time. Therefore, the system is designed to withstand the loss of any single piece of equipment and to continue operating without impacting any customers. That is, the system is designed to withstand a single contingency.

Taken together, these two factors result in a dynamic reactive-power requirement. The loss of a generator or a major transmission line can have the compounding effect of reducing the reactive supply and, at the same time, reconfiguring flows such that the system is consuming additional reactive power. At least a portion of the reactive supply must be capable of responding quickly to changing reactive-power demands and to maintain acceptable voltages throughout the system. Thus, just as an electrical system requires real-power reserves to respond to contingencies, so too it must maintain reactive-power reserves.

Loads can also be both real and reactive. The reactive portion of the load could be served from the transmission system. As explained in the Appendix, reactive loads incur more voltage drop and reactive losses in the transmission system than do similar-size (MVA) real loads. Vertically integrated utilities often include charges for provision of reactive power to loads in their rates. With restructuring, the trend is to restrict loads to operation at near zero reactive power demand (a 1.0 power factor). ${ }^{*}$ The California independent system operator (ISO) proposal limits loads to power factors between 0.97 lagging (absorbing reactive power) and 0.99 leading (generating reactive power) (Pacific Gas and Electric et al. 1997).

Voltage control could be split into the same set of services as real power because of the symmetry between real and reactive power (Alvarado 1996). Such a split would result in (1) a reactive-power service similar to regulation to compensate for rapid, uncorrelated fluctuations with a time scale ranging from a few seconds to several minutes; (2) a service similar to load following to compensate for slower, usually correlated fluctuations with a time scale ranging from several minutes to a few hours; (3) insurance services similar to operating reserves to compensate for equipment failures with a time scale ranging from several seconds to an hour or two; and (4) backup supply with a time scale of one to many hours. A service similar to energy imbalance would account for participants that fail to meet their obligations. A lossreplacement service would not be required because all of voltage control addresses the transmission system's requirements for reactive power.

*The power factor (PF) is the ratio of real power (in MW) to apparent power (MVA). Apparent power is related to real and reactive power (MVAR) according to $\left.M V A=\sqrt{\left[(M W)^{2}\right.}+(M V A R)^{2}\right]$. 
The significant differences between the real and reactive services are:

- Real power can be delivered over much greater distances so the supplying resources are not as location constrained, whereas reactive resources must be distributed throughout the power system.

- Generation of real power requires the conversion from some other energy resource, such as chemical or nuclear fuel, sunlight, or a mechanical resource like wind or water flow, whereas reactive power requires almost no "fuel" to produce.

Much of the complication associated with voltage control comes from combining these various aspects into a single service. Rather than splitting the ancillary service along functional lines, FERC and the industry have elected to split the service based on commercial ownership of the resources that supply the service. The requirements and compensation for generationbased resources fall under what FERC calls Reactive Supply and Voltage Control from Generation Sources. Transmission-based resources are addressed under the general transmission tariff. The range of physical requirements (speed of response, need for contingency reserve, etc.) still exist, but they are not addressed in the basic definitions as they are for real-power services.

As with most ancillary services, the need for voltage control stems from an overall system requirement, requires resources that are capable of supplying that need, and must have a central-control function directing those resources to meet the requirement. Suppliers of the resources, in this case generators with reactive-power capabilities, are not able to independently determine the system's voltage-control needs. Only the system operator has sufficient information to know the system requirements, both current and contingency, and to deploy those resources effectively. Similarly, while service requirements result from customer choices in terms of load patterns and generation choices, the customers do not have sufficient information about the configuration of the transmission system or the actions of other customers to know ahead of time what reactive-power requirements will result from their choices. Again, the system operator is needed to deploy resources to meet requirements and to transmit appropriate price signals to customers.

Generators and various types of transmission equipment are used to maintain voltages throughout the transmission system. Injecting reactive power into the system raises voltages, and absorbing reactive power lowers voltages. Voltage-support requirements are a function of the locations and magnitudes of generator outputs and customer loads and of the configuration of the transmission system. These requirements can differ substantially from location to location and can change rapidly as the location and magnitude of generation and load change. At very low levels of system load, transmission lines act as capacitors and increase voltages. At high levels of load, however, transmission lines absorb reactive power and thereby lower voltages. Most transmission-system equipment (e.g., capacitors, inductors, and tap-changing transformers) is relatively static and can respond to changes in voltage-support requirements 
only slowly and in discrete steps. Some transmission-system equipment [e.g., static synchronous compensators (STATCOMs) and static VAR compensators (SVCs)] and generators can respond within cycles to changing reactive-power requirements.

Data from Detroit Edison demonstrate the complexities of voltage control and the production and absorption of reactive power (Davis 1994). Figure 1 shows the distribution of generation and transmission reactive-power sources and sinks at the time of system peak. Working from left to right, Detroit Edison's generating units provide 2910 MVAR of reactive power to the system. However, the stepup transformers at the generators absorb 1100 MVAR. The natural capacitance of the transmission system provides 1680 MVAR, more than offset by the natural inductance of the transmission lines and transformers, which absorb 2000 MVAR. Capacitors and other transmission reactive-power equipment provide 5040 MVAR. Finally, customer loads absorb 6530 MVAR. Thus, at the time of system peak, Detroit Edison was providing $3100 \mathrm{MVAR}$ of voltage support. This MVAR loss was 3.6 times greater than the real-power loss of $860 \mathrm{MW}$.

REAL LOSSES $=860 \mathrm{MW}$

REACTIVE LOSSES $=3100$ MVAR

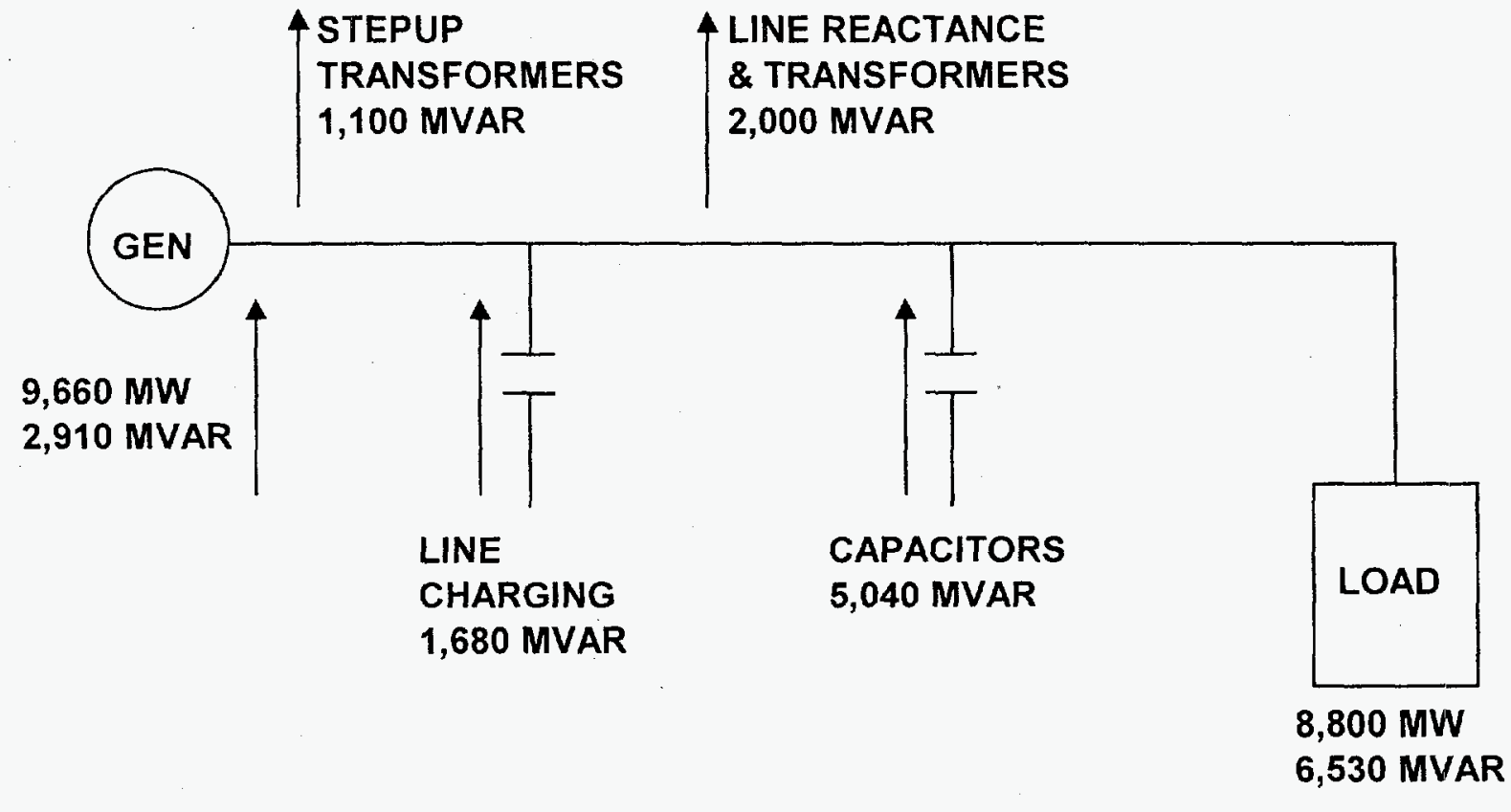

97009

Fig. 1. Production and absorption of reactive power at times of system peak for Detroit Edison. 
This report is aimed primarily at regulators and others that may lack electricalengineering backgrounds. Our primary goal is to present the basics of voltage control and to demonstrate the importance of this ancillary service for both reliability and commerce. Electrical engineers and system operators, although they will learn little about the technical aspects of this service, may benefit from our discussion of how the economics and markets for this service may change as the electricity industry is restructured.

The report proceeds as follows. Chapter 2 presents the overall system requirements for voltage control. Chapter 3 describes and contrasts the various types of generation and transmission equipment that can produce and absorb reactive power. Chapter 4 discusses some of the recent activities undertaken by power pools and regional reliability councils to modify the systems that acquire and deploy reactive-power resources for an increasingly competitive electricity industry. Finally, Chapter 5 presents our conclusions and recommendations for additional work. 


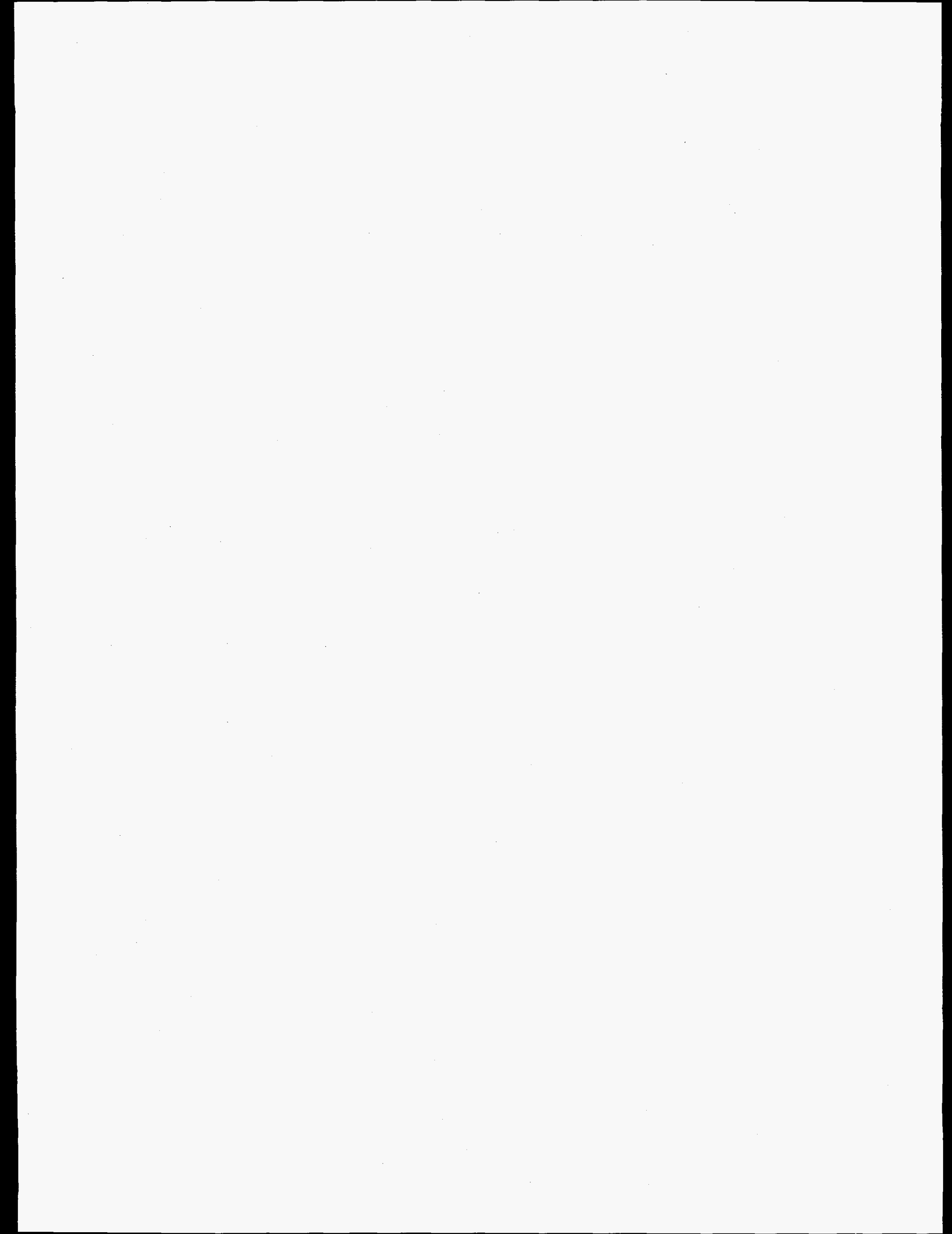




\section{TRANSMISSION-SYSTEM VOLTAGE CONTROL}

In moving power from generators to loads, the transmission network introduces both real and reactive losses. Housekeeping loads at substations (such as security lighting and space conditioning) and transformer excitation losses are roughly constant (i.e., independent of the power flows on the transmission system). Transmission-line losses, on the other hand, depend strongly on the amount of power being transmitted.

Real-power losses arise because aluminum and copper (the materials most often used for transmission lines) are not perfect conductors; they have resistance. The reactive-power nature of transmission lines is associated with the geometry of the conductors themselves (primarily the radius of the conductor) and the geometry of the conductor configuration (the distances between each conductor and ground and the distances among conductors).

The reactive-power behavior of transmission lines is complicated by their inductive and capacitive characteristics. As shown in Fig. 2, at low line loadings, the capacitive effect dominates, and generators and transmission-related reactive equipment must absorb reactive power to maintain line voltages within their appropriate limits. On the other hand, at high line loadings, the inductive effect dominates, and generators, capacitors, and other reactive devices must produce reactive power. The balance point at which the inductive and capacitive effects cancel each other (what is called surge-impedance loading) is typically about $40 \%$ of the line's thermal capacity."

Figure 2 also shows that at both low and high line loadings (but not around the surgeimpedance loading), reactive losses are greater than real losses. At full line loading, reactive losses are five times greater than real losses for a $230-\mathrm{kV}$ line and nine times higher for a 345 $\mathrm{kV}$ line. (At $50 \%$ of line loading, the factors are two and four for the 230 - and 345-kV lines, respectively.)

If uncompensated, these line losses reduce the amount of real power that can be transmitted from generators to loads. Figure 3 shows how transmission-line capacity decreases

"The thermal limit is the loading point (in MVA) above which real power losses in the equipment will overheat and damage the equipment. Most transmission elements (e.g., conductors and transformers) have normal thermal limits below which the equipment can operate indefinitely without loss of lifetime. These types of equipment also have one or more emergency limits to which the equipment can be loaded for several hours with minimal loss of lifetime. 


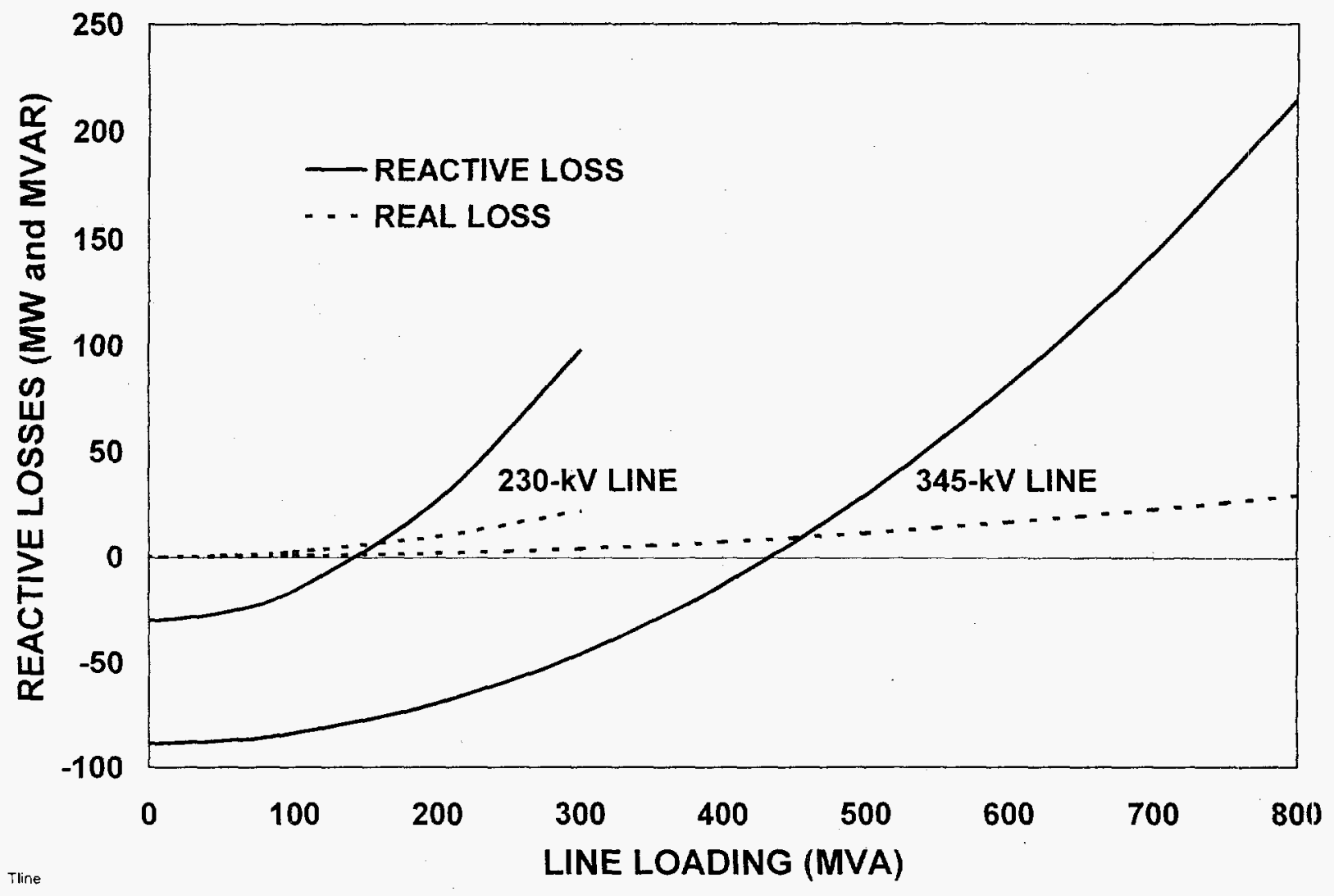

Fig. 2. Transmission lines supply reactive power to the system when lightly loaded but absorb reactive power when heavily loaded. These results are for a 100-mile line with voltages supported at both ends.

as the line length increases if there is no voltage support (injection or absorption of reactive power) on the line. At short distances, the line's capacity is limited by thermal considerations; at intermediate distances the limits are related to voltage drop; and beyond roughly 300 to 350 miles, stability limits dominate. A study conduced by the East Central Area Reliability Coordination Agreement (ECAR 1997) showed that the addition of series capacitors to boost voltages would increase the capacity of a particular transmission line by about $60 \%$.

This discussion has thus far dealt with transmission lines only, which is enough to demonstrate the complexities associated with real and reactive losses, distance from generation to load, line capacity, line loading, and average vs incremental losses. The situation is actually much more complicated because transmission networks contain many pieces of equipment in addition to high-voltage lines, including transformers, switches, and capacitors. In addition, network flows are constantly changing, affecting both real and reactive losses.

Contingency considerations further limit voltage acceptability. Using the 1998 MAIN (Mid-America Interconnected Network) summer base loadflow case, we examined expected voltages at a midwestern nuclear plant. Not surprisingly, the worst contingency in the area is the loss of the generation itself. This nuclear plant has both $138-\mathrm{kV}$ and $345-\mathrm{kV}$ busses. The 


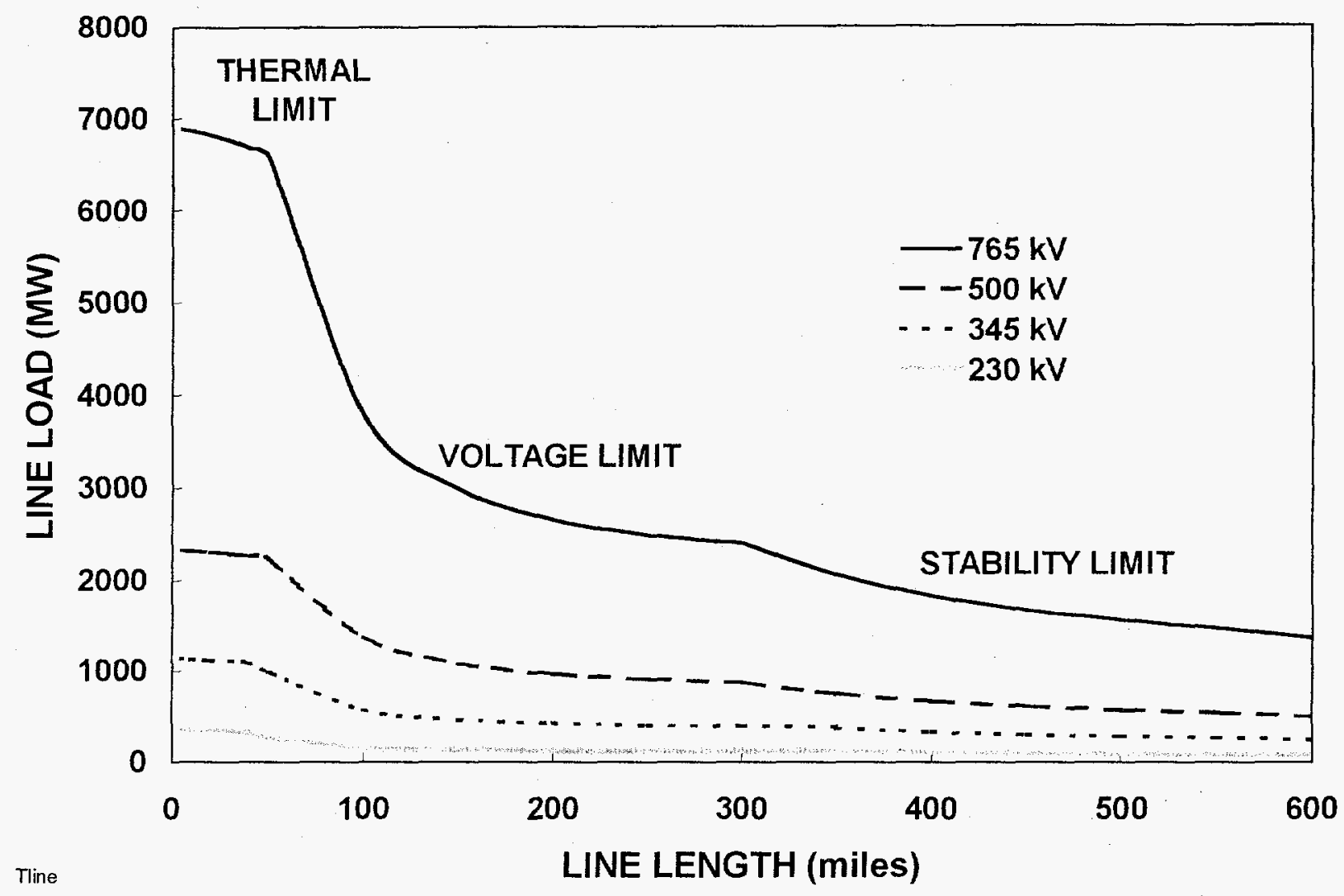

Fig. 3. Absent reactive compensation to maintain voltages, transmission-line capacity is limited to shorter lengths.

generation is connected, through a stepup transformer, to the $345-\mathrm{kV}$ bus. Prior to the contingency, the plant is generating $930 \mathrm{MW}$ and 283 MVAR. Results of the loadflow simulations are presented in Table 1.

Table 1. Contingency voltage response at a midwestern nuclear generator

\begin{tabular}{lcc}
\hline & \multicolumn{2}{c}{ Per unit voltage } \\
\cline { 2 - 3 } & $345 \mathrm{kV}$ & $138 \mathrm{kV}$ \\
\hline Precontingency: plant delivering 930 MW and 283 MVAR & 1.040 & 0.975 \\
to the 345-kV bus & & \\
Postcontingency: plant trips offline & 0.998 & 0.939 \\
Voltage drop & 0.042 & 0.036 \\
Response to 100 MVAR support & 1.010 & 1.001 \\
Voltage rise/100 MVAR & 0.012 & 0.062 \\
\hline
\end{tabular}


Several interesting characteristics of voltage control can be seen in Table 1. The 138-kV voltage that seemed marginally adequate prior to the contingency is unacceptable afterwards. In fact, because of the voltage sensitivity of equipment at the nuclear plant and a need for 1.) per unit $(\mathrm{pu})$ voltages (significantly higher than the usual 0.95 -pu requirement), the postcontingency $345-\mathrm{kV}$ voltage is not adequate in this case." The voltage drop is more severe on the $345-\mathrm{kV}$ bus $(0.042 \mathrm{pu})$, which is directly supported by the generation; but the drop on the $138-\mathrm{kV}$ bus $(0.036 \mathrm{pu})$ is nearly as large, and the $138-\mathrm{kV}$ bus is electrically remote.

Postcontingency voltages on either bus can be raised above 1.0 pu by injecting 100 MVAR at that bus. The response at the $138-\mathrm{kV}$ bus, however, is more than five times the response at the $345-\mathrm{kV}$ bus.

The distance-related line-loading limitation shown in Fig. 3 results in concern about local voltage support in a given area. Figure 4 is an example nomogram that shows system operators how much remotely generated power can be imported into an area in western

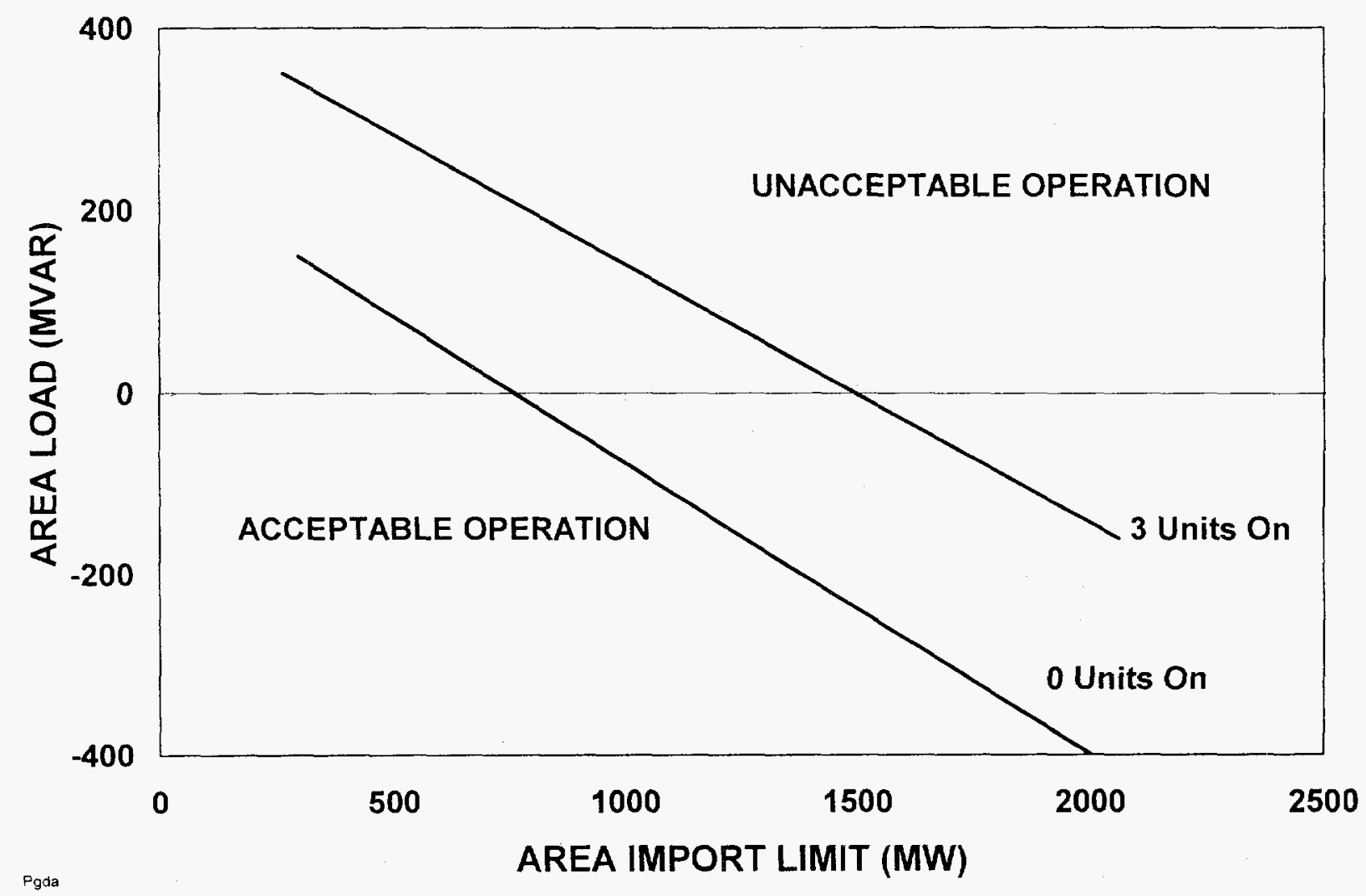

Fig. 4. Real-power import limits for this area depend strongly on the reactive-power capability of local generating units.

"Voltages are often expressed in per-unit $(\mathrm{pu})$ terms, normalized to the nominal voltage rating of the piece of equipment. 
Kentucky based on the number of local generating units that are currently operating. Imports must be constrained to the area below and to the left of the appropriate generation-limit line. With no local generating units online and an area reactive load of $50 \mathrm{MVAR}$, imports must be limited to $660 \mathrm{MW}$.

Each local generating unit is capable of producing 70 MVAR. The reactive capability available under contingency conditions is what is important, not the amount of support the units are currently providing. In this area, each MVAR of additional capability facilitates the importation of an additional $3.5 \mathrm{MW}$ of real power. 



\section{VOLTAGE-CONTROL EQUIPMENT}

The power-system designer and operator have several devices available that can be used to control voltages by injecting, absorbing, or forcing the flow of reactive power. These devices differ in several important characteristics: response speed, continuity of control, response to system voltage changes, and capital and operating costs (Table 2).

Table 2. Characteristics of voltage-control equipment

\begin{tabular}{|c|c|c|c|c|c|}
\hline \multirow{2}{*}{$\begin{array}{l}\text { Equipment } \\
\text { type }\end{array}$} & \multirow{2}{*}{$\begin{array}{l}\text { Speed of } \\
\text { response }\end{array}$} & \multirow{2}{*}{$\begin{array}{l}\text { Ability to support } \\
\text { voltage }\end{array}$} & \multicolumn{3}{|c|}{ Costs } \\
\hline & & & $\begin{array}{c}\text { Capital } \\
\text { (per kVAR) }\end{array}$ & $\begin{array}{l}\text { Oper- } \\
\text { ating }\end{array}$ & $\begin{array}{l}\text { Oppor- } \\
\text { tunity }\end{array}$ \\
\hline Generator & Fast & $\begin{array}{l}\text { Excellent, additional } \\
\text { short-term capacity }\end{array}$ & $\begin{array}{l}\text { Difficult to } \\
\text { separate }\end{array}$ & High & Yes \\
\hline $\begin{array}{l}\text { Synchronous } \\
\text { condenser }\end{array}$ & Fast & $\begin{array}{l}\text { Excellent, additional } \\
\text { short-term capacity }\end{array}$ & $\$ 30-35$ & High & No \\
\hline Capacitor & $\begin{array}{l}\text { Slow, } \\
\text { stepped }\end{array}$ & Poor, drops with $\mathrm{V}^{2}$ & $\$ 8-10$ & Very low & No \\
\hline $\begin{array}{l}\text { Static VAR } \\
\text { compensator }\end{array}$ & Fast & Poor, drops with $\mathrm{V}^{2}$ & $\$ 45-50$ & Moderate & No \\
\hline STATCOM & Fast & Fair, drops with V & $\$ 50-55$ & Moderate & No \\
\hline $\begin{array}{l}\text { Distributed } \\
\text { generation }\end{array}$ & Fast & Fair, drops with V & $\begin{array}{l}\text { Difficult to } \\
\text { separate }\end{array}$ & High & Yes \\
\hline
\end{tabular}

\section{GENERATION}

An electric-power generator's primary function is to convert fuel (or other energy resource) into electric power. Almost all generators ${ }^{*}$ also have considerable control over their terminal voltage and reactive-power output. Payment for the use of this resource is the specific focus of FERC's voltage control from generation service.

*Throughout this report we are discussing synchronous machines rather than induction or other less common generators. 
The ability of a generator to provide reactive support depends on its real-power production. Figure 5 shows the combined limits on real and reactive production for a typical generator (Rustebakke 1983). Like most electric equipment, generators are limited by their current-carrying capability. Near rated voltage, this capability becomes an MVA limit for the armature of the generator rather than a MW limitation, shown as the armature heating limit in Fig. 5. Production of reactive power involves increasing the magnetic field to raise the generator's terminal voltage. Increasing the magnetic field requires increasing the current in the rotating field winding. This too is current limited, resulting in the field-heating limit shown in the figure. Absorption of reactive power is limited by the magnetic-flux pattern in the stator, which results in excessive heating of the stator-end iron, the core-end heating limit. The synchronizing torque is also reduced when absorbing large amounts of reactive power, which can also limit generator capability to reduce the chance of losing synchronism with the system.

The generator prime mover (e.g., the steam turbine) is usually designed with less capacity than the electric generator, resulting in the prime-mover limit in Fig. 5. The designers recognize that the generator will be producing reactive power and supporting system voltage most of the time. Providing a prime mover capable of delivering all the mechanical power the generator can convert to electricity when it is neither producing nor absorbing reactive power would result in underutilization of the prime mover.

At maximum real-power output, the generator shown in Fig. 5 can produce 0.62 MVAR for every megawatt of real-power output, based on the 0.85 lagging power-factor limit. Or it can absorb 0.41 MVAR for every megawatt of real-power output, based on the 0.93 leading power-factor limit. To produce or absorb additional VARs beyond these limits would require a reduction in the real-power output of the unit.

Control over the reactive output and the terminal voltage of the generator is provided by adjusting the DC current in the generator's rotating field. Control can be automatic, continuous, and fast." The inherent characteristics of the generator help maintain system voltage. At any given field setting, the generator has a specific terminal voltage it is attempting to hold. If the system voltage declines, the generator will inject reactive power into the power system, tending to raise system voltage. If the system voltage rises, the reactive output of the generator will drop, and ultimately reactive power will flow into the generator, tending to lower system voltage. The voltage regulator will accentuate this behavior by driving the field current in the appropriate direction to obtain the desired system voltage. Because most of the reactive

"The leading power factor limit is 0.93 , rather than the 0.95 shown in Fig. 5 , because the former is the prime-mover limit. The 0.95 power factor shows the intersection of the core-end heating limit and the armature-heating limit, not the limit on real-power production.

"Generator reactive output can change much more rapidly than the system's need for voltage control, which is on the order of a few seconds. 


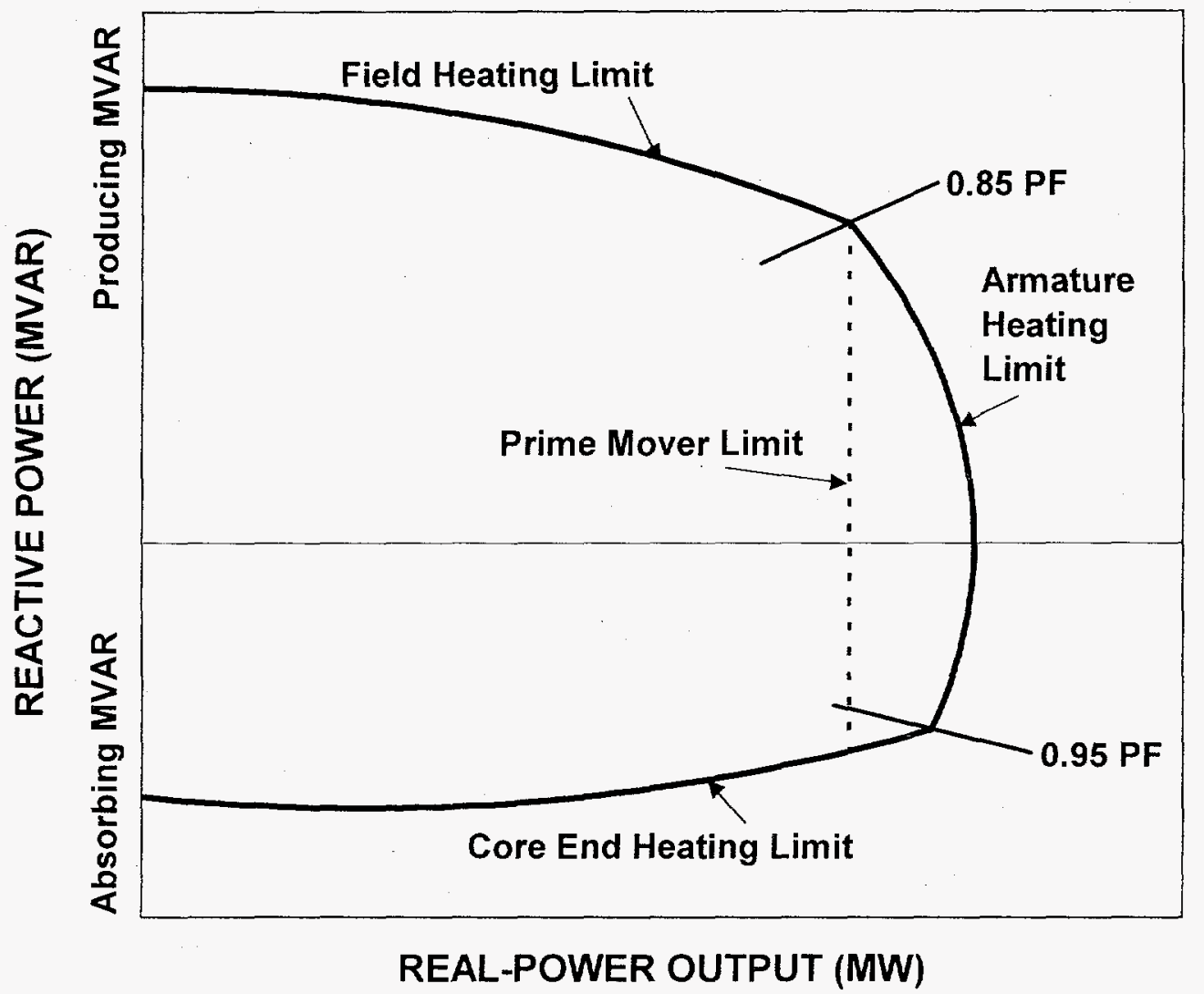

Fig. 5. Reactive-power capability depends on real-power production for a synchronous generator.

limits are thermal limits associated with large pieces of equipment, significant short-term extra reactive-power capability usually exists."

Historically, only the capital and operating costs that could be associated with the extra equipment (e.g., parts of the voltage regulator, exciter, stator, and rotor plus the operating costs associated with field losses) required for voltage control were charged to the voltage-control function. In a restructured industry, the opportunity costs associated with reduced real-power sales when excessive reactive power is required will be an important component of the total cost of providing voltage control from generation." Generator reactive capability is determined during the design of the machine. Because capital costs are involved in providing this

"Power-system stabilizers also control generator field current and reactive-power output in response to oscillations on the power system. This function is a part of the network-stability ancillary service.

${ }^{*}$ A recent study of ancillary-service markets suggests that the costs and prices for voltage support will be highly nonlinear with system load (Hirst and Kirby 1997). At very high levels of system load, the opportunity cost of voltage support will far exceed the embedded cost. 
capability, builders of new generating units will likely not include voltage-support capability unless (1) the market or a regulated tariff compensates the generators or (2) voltage-support capability is a requirement of connecting to the grid.

\section{SYNCHRONOUS CONDENSERS}

Every synchronous machine (motor or generator) has the reactive-power capabilities discussed above. Synchronous motors are occasionally used to provide voltage support to the power system as they provide mechanical power to their load. Some combustion turbines and hydro units are designed to allow the generator to operate without its mechanical power source simply to provide the reactive-power capability to the power system when the real-power generation is unavailable or not needed. Synchronous machines that are designed exclusively to provide reactive support are called synchronous condensers. Synchronous condensers have all of the response speed and controllability advantages of generators without the need to construct the rest of the power plant (e.g., fuel-handling equipment and boilers). Because they are rotating machines with moving parts and auxiliary systems, they may require significantly more maintenance than static alternatives. They also consume real power equal to about $3 \%$ of the machine's reactive-power rating. That is, a 50-MVAR synchronous condenser requires about $1.5 \mathrm{MW}$ of real power.

\section{CAPACITORS AND INDUCTORS}

Capacitors and inductors (which are sometimes called reactors) are passive devices that generate or absorb reactive power (how they do so is explained in the Appendix). They accomplish this without significant real-power losses or operating expense. The output of capacitors and inductors is proportional to the square of the voltage. Thus, a capacitor bank (or inductor) rated at $100 \mathrm{MVAR}$ will produce (or absorb) only $90 \mathrm{MVAR}$ when the voltage dips to 0.95 pu but it will produce (or absorb) 110 MVAR when the voltage rises to $1.05 \mathrm{pu}$. This relationship is helpful when inductors are employed to hold voltages down. The inductor absorbs more when voltages are highest and the device is needed most. The relationship is unfortunate for the more common case where capacitors are employed to support voltages. In the extreme case, voltages fall, and capacitors contribute less, resulting in a further degradation in voltage and even less support from the capacitors; ultimately, voltage collapses and outages occur.

Inductors are discrete devices designed to absorb a specific amount of reactive power at a specific voltage. They can be switched on or off but offer no variable control.

Capacitor banks are composed of individual capacitor cans, typically $200 \mathrm{kVAR}$ or less each. The cans are connected in series and parallel to obtain the desired capacitor-bank voltage and capacity rating. Like inductors, capacitor banks are discrete devices but they are often configured with several steps to provide a limited amount of variable control. 


\section{STATIC VAR COMPENSATORS (SVCs)}

An SVC combines conventional capacitors and inductors with fast switching capability. Switching takes place in the subcycle timeframe (i.e., in less than 1/60 of a second), providing a continuous range of control. The range can be designed to span from absorbing to generating reactive power. Consequently, the controls can be designed to provide very fast and effective reactive support and voltage control.

Because SVCs use capacitors, they suffer from the same degradation in reactive capability as voltage drops. They also do not have the short-term overload capability of generators and synchronous condensers. SVC applications usually require harmonic filters to reduce the amount of harmonics injected into the power system.

\section{STATIC SYNCHRONOUS COMPENSATORS (STATCOMs)}

The STATCOM is a solid-state shunt device that generates or absorbs reactive power and is one member of a family of devices known as flexible AC transmission system (FACTS) devices (Kessinger 1997). ${ }^{*}$ The STATCOM is similar to the SVC in response speed, control capabilities, and the use of power electronics. Rather than using conventional capacitors and inductors combined with fast switches, however, the STATCOM uses power electronics to synthesize the reactive power output. Consequently, output capability is generally symmetric, providing as much capability for production as absorption. The solid-state nature of the STATCOM means that, similar to the SVC, the controls can be designed to provide very fast and effective voltage control (Purucker 1997).

While not having the short-term overload capability of generators and synchronous condensers, STATCOM capacity does not suffer as seriously as SVCs and capacitors do from degraded voltage. STATCOMs are current limited so their MVAR capability responds linearly to voltage as opposed to the voltage-squared relationship of SVCs and capacitors. This attribute greatly increases the usefulness of STATCOMs in preventing voltage collapse.

\section{DISTRIBUTED GENERATION}

Distributing generation resources throughout the power system can have a beneficial effect if the generation has the ability to supply reactive power. Without this ability to control reactive-power output, performance of the transmission and distribution system can be degraded.

Induction generators are an attractive choice for small, grid-connected generation, primarily because they are relatively inexpensive. They are also easy to synchronize and have

*FACTS is the use of high-speed solid-state technologies to control transmission equipment, thereby improving reliability and increasing capacity. 
mechanical characteristics that are appealing for some applications (wind, for example). They also absorb reactive power rather than generate it, and are not controllable. If the output from the generator fluctuates (as wind does), the reactive demand of the generator fluctuates as well, compounding voltage-control problems for the transmission system. Induction generators can be compensated with static capacitors, but this strategy does not address the fluctuation problem or provide controlled voltage support.

Many distributed generation resources are now being coupled to the grid through solidstate power electronics to allow the prime mover's speed to vary independently of the powersystem frequency. For wind, this use of solid-state electronics can improve the energy capture. For gas-fired microturbines, this equipment allows them to operate at very high speeds. Photovoltaics generate direct current and require inverters to couple them to the power system. Energy-storage devices (e.g., batteries, flywheels, and superconducting magnetic-energy storage devices) are often distributed as well and require solid-state inverters to interface with the grid. This increased use of a solid-state interface between the devices and the power system has the added benefit of providing full reactive-power control, similar to that of a STATCOM. In fact, most devices do not have to be providing active power for the full range of reactive control to be available. The generation resource can be out of service while the reactive component is fully functional. This technological development (solid-state power electronics) has turned a potential problem into a benefit, allowing distributed resources to contribute to voltage control.

\section{TRANSFORMERS}

Transformers provide the capability to raise alternating-current generation voltages to levels that make long-distance power transfers practical and then lowering voltages back to levels that can be distributed and used. The primary coils of the transformer convert electric power into a magnetic field circulating in an iron core. The secondary coils reconvert the magnetic field into electric power. The ratio of the number of turns in the primary to the number of turns in the secondary determines the ratio of the primary voltage to the secondary voltage. By tapping the primary or secondary coil at various points, the ratio between the primary and secondary voltage can be adjusted. Transformer taps can be either fixed or adjustable under load through the use of a load-tap changer (LTC). Tap capability is selected for each application during transformer design. Fixed or variable taps often provide $\pm 10 \%$ voltage selection, with fixed taps typically in 5 steps and variable taps in 32 steps.

Transformer-tap changers can be used for voltage control, but the control differs from that provided by reactive sources. Transformer taps can force voltage up (or down) on one side of a transformer, but it is at the expense of reducing (or raising) the voltage on the other side. The reactive power required to raise (or lower) voltage on a bus is forced to flow through the transformer from the bus on the other side. Figure 6 shows this relationship for a $1200-\mathrm{MVA}$ transformer on the MAIN/SERC border. In this example, the transformer is moving approximately $700 \mathrm{MW}$ from a $345-\mathrm{kV}$ bus in MAIN to a $500-\mathrm{kV}$ bus in SERC. At the nominal 


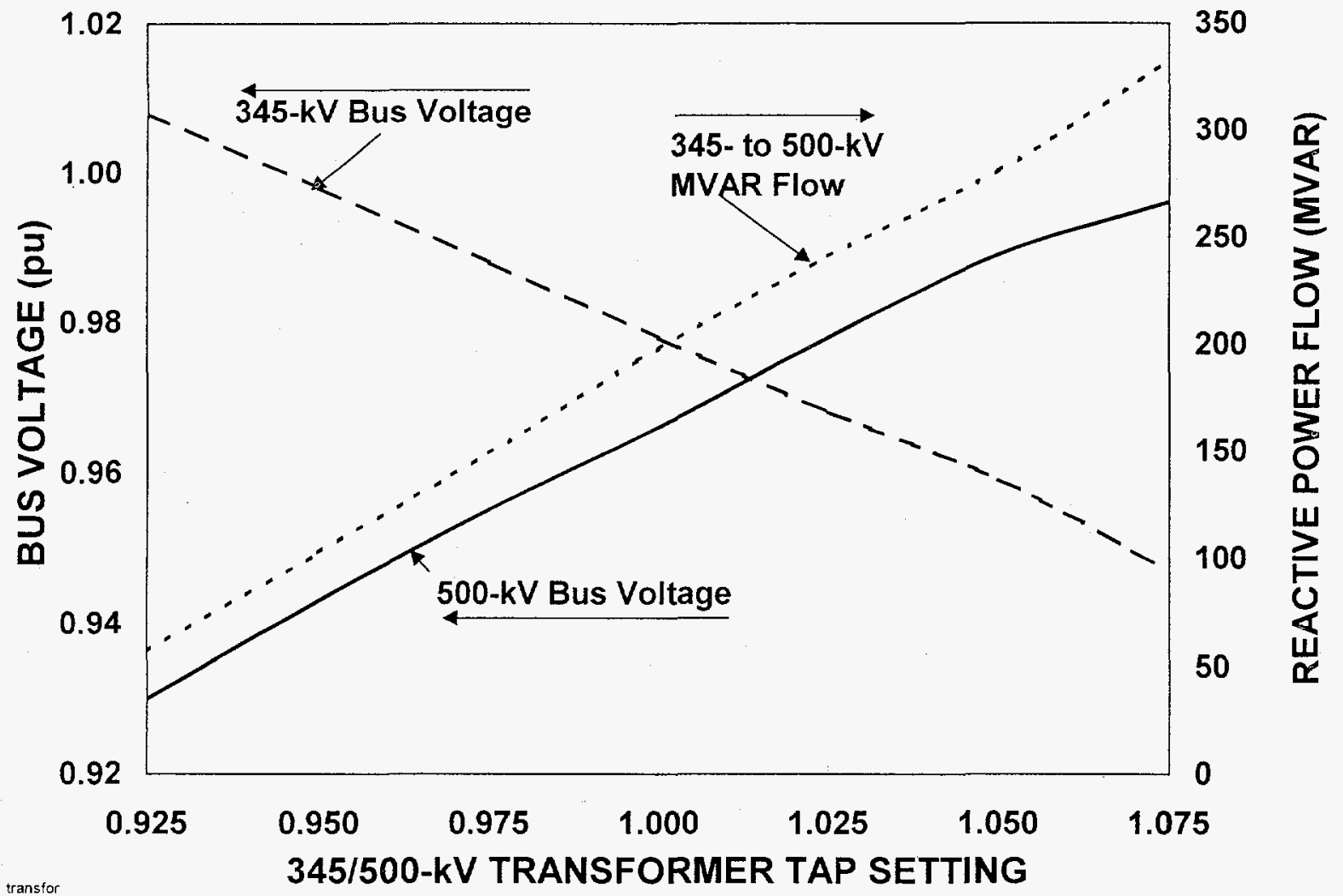

Fig. 6. Changes in voltage levels and reactive-power flow in response to changes in the tap positions for a 1200-MVA transformer.

$\operatorname{tap}(1.0)$, the voltage on the $345-\mathrm{kV}$ bus is $0.98 \mathrm{pu}$, while the voltage on the $500-\mathrm{kV}$ bus is 0.97 $\mathrm{pu}$, and $198 \mathrm{MVAR}$ is flowing from the $345-\mathrm{kV}$ bus to the $500-\mathrm{kV}$ bus. Voltage can be raised to $1.0 \mathrm{pu}$ on the $500-\mathrm{kV}$ bus by raising the tap setting to 1.075 , but this reduces the $345-\mathrm{kV}$ bus voltage from 0.98 to $0.95 \mathrm{pu}$ and increases the reactive-power flow from the $345-\mathrm{kV}$ bus to the $500-\mathrm{kV}$ bus by 134 MVAR. Conversely, voltage on the $345-\mathrm{kV}$ bus can be raised to 1.0 pu by reducing the tap setting to 0.95 , but this reduces the $500-\mathrm{kV}$ bus voltage from 0.97 to $0.94 \mathrm{pu}$ and reduces the reactive power flow from the $345-\mathrm{kV}$ bus to the $500-\mathrm{kV}$ bus by $95 \mathrm{MVAR}$.

The retail tariffs that most utilities offer their large customers require that voltages at load buses be maintained near 1.0 pu and not drop below 0.95 pu under contingency conditions. Generator buses are usually not allowed to rise above $1.056 \mathrm{pu}$. Voltages at other points in the transmission system are constrained on the high side by equipment insulation and on the low side by concerns over excess current and voltage collapse. Within these constraints, transformer taps and LTCs can be invaluable for managing voltages throughout a power system.

The transformer must be taken out of service and de-energized to adjust the fixed taps, a time-consuming and inconvenient process. Consequently, fixed taps are useful when compensating for load growth and other long-term shifts in system use. LTCs are used for more-rapid adjustments, such as compensating for the voltage fluctuations associated with the 
daily load cycle. While LTCs could potentially provide rapid voltage control, their performance is normally intentionally degraded. With an LTC, tap changing is accomplished by opening and closing contacts within the transformer's tap-changing mechanism. For the conditions shown in Fig. 6, this process involves making and breaking load currents of over 800 amps. Because taps must be moved sequentially, the tap-changing contacts experience wear. To keep maintenance requirements reasonable, response (initial response and sequential-step response) is generally delayed for 30 seconds or longer. This delay prevents the LTC from responding to momentary fluctuations, such as motor-starting surges. It also allows time after each tap step for other control equipment (e.g., generator-field controls and automatic capacitor switching) to finish responding to the new conditions before subsequent tap steps are taken.

\section{DIFFERENCES AMONG EQUIPMENT TYPES}

Generators, synchronous condensers, SVCs, and STATCOMs all provide fast, continuously controllable reactive support and voltage control. LTC transformers provide nearly continuous voltage control but they are slow. Because the transformer moves reactive power from one bus to another, the control gained at one bus is at the expense of the other. Capacitors and inductors are not variable and offer control only in large steps.

An unfortunate characteristic of capacitors and capacitor-based SVCs is that output drops dramatically when voltage is low and support is needed most. The output of a capacitor, and the capacity of an SVC, is proportional to the square of the terminal voltage. STATCOMs provide more support under low-voltage conditions than do capacitors or SVCs because they are current-limited devices and their output drops linearly with voltage. The output of rotating machinery (i.e., generators and synchronous condensers) rises with dropping voltage unless the field current is actively reduced. Generators and synchronous condensers generally have additional emergency capacity that can be used for a limited time.

Voltage-control characteristics favor the use of generators and synchronous condensers. Costs, on the other hand, favor capacitors. Generators have extemely high capital costs because they are designed to produce real power, not reactive power. Even the incremental cost of obtaining reactive support from generators is high, although it is difficult to unambiguously separate reactive-power costs from real-power costs. Operating costs for generators are high as well because they involve real-power losses. Finally, because generators have other uses, they experience opportunity costs when called upon to simultaneously provide high levels of both reactive and real power. Synchronous condensers have the same costs as generators; but, because they are built solely to provide reactive support, their capital costs do not include the prime mover or the balance of plant and they incur no opportunity costs. SVCs and STATCOMs are high-cost devices, as well, although their operating costs are lower than those for synchronous condensers and generators. 


\section{RESOURCE CONTROL AND MARKET STRUCTURES}

System operation has three objectives when managing reactive power and voltages. First, it must maintain adequate voltages throughout the transmission system for both current and contingency conditions. Second, it seeks to minimize congestion of real-power flows. Third, it seeks to minimize real-power losses. These were the system-control objectives before restructuring, and they will continue to be the objectives after restructuring of the U.S. electricity industry. However, the mechanisms that system operators use to acquire and deploy reactive-power resources are changing. These mechanisms must be fair to all parties as well as effective. Further, they must be demonstrably fair.

Historically, system operations, generators, transmission devices, and the transmission system itself were all owned and operated by the same entity. In the future, the entities that own and operate generation may differ from those that own transmission, and both may differ from the system operator (which likely will control the transmission system). These changes will require the creation of new market structures, including rules and requirements for connection to the transmission system and the operation of certain equipment. In spite of these rule changes, the system operator must have the authority to deploy resources to meet the system's voltage-control objectives at minimum cost.

Not surprisingly, more progress has been made in addressing the technical objectives of managing voltages than in developing market structures to perform this function in a restructured industry. The operating policies of the North American Electric Reliability Council (NERC 1996) focus on the concept of control-area responsibility for controlling voltage and reactive resources, allowing control areas to develop appropriate rules. Control areas are to maintain sufficient reactive resources to support voltages under first-contingency conditions. Each control area should take care of its own needs and avoid placing a burden on other control areas. NERC policies offer little guidance on what resources should be available or how the system operator should acquire and deploy them, leaving these decisions to the regional reliability councils and the individual control areas.

\section{TECHNICAL GUIDANCE AND COMPENSATION RULES}

Regional reliability councils differ in the level of detailed guidance they offer their members concerning voltage control. The Southwest Power Pool (1997), the Southeastern Electric Reliability Council (1995), and the Florida Reliability Coordinating Council (1996) provide only general guidance to their members on how to maintain adequate voltage support during normal and credible contingency conditions. Individual control-area operators use the authority of these directives to authorize specific actions directed at voltage support. The Electric Reliability Council of Texas (1997) provides additional direction concerning required 
generator capability and authorizes control-area operators to use each generator's full reactive capability to maintain system voltages.

Regions containing tight power pools, such as the Mid-Atlantic Area Council and the Northeast Power Coordinating Council along with their member pools, have more detailed rules concerning both generator-capability requirements and system operations to maintain voltages (PJM 1997a; NPCC 1996; NEPOOL 1996). These rules govern which conditions to study when determining voltage requirements and generator-reactive-capability requirements as well as the use of these resources. Rules governing voltage-control actions to be taken by system operators generally use the lowest-cost resources first and delay expensive actions, such as redispatching generator real-power output. When the problem is addressed at all, generators are typically compensated at cost if they are required to adjust their real-power output to support voltages. The NPCC (1992) operating guide provides a typical example of the order of control actions:

Low-cost transmission-system and generation-control actions

- adjust transformer taps

- switch capacitors/reactors

- adjust SVCs

- use full reactive capability of online generators

Higher-cost adjustments to economic energy production

- start additional generation

- modify economy transactions with other areas and/or deviate from economic dispatch

- operate hydro units as synchronous condensers, where possible

- reschedule pumped-hydro units to generate or pump

- purchase energy

Adjustments to the transmission-system configuration

- switch out internal transmission lines provided operating security limits are not violated

The Pennsylvania-New Jersey-Maryland Interconnection (PJM) offers an interesting example of inter-region cooperation in reactive-power management. Three off-system contingencies have been identified that can have a larger impact on PJM voltages than can the largest on-system contingency (PJM 1997b). " These contingencies have been jointly studied and agreed to by the systems in New York, New England, and PJM. When conditions are such that PJM would be vulnerable to one of these contingencies, the host system notifies PJM, and PJM calculates limits for the host to operate under to prevent unacceptable postcontingericy voltages within the PJM region. Although PJM takes actions to minimize the impact on the host system, PJM does not operate generation "off-cost" to maintain voltage margins.

"These off-system contingencies are: simultaneous loss of all Hydro Quebec (HQ) high-voltage DC interconnections linked to the HQ AC system (Canada), loss of the Phase II (Sandy Pond) high-voltage DC tie (Massachusetts), and loss of multiple Millstone nuclear generating units (Connecticut). Under certain conditions, any one of these contingencies has worse voltage consequences for the PJM system than would the worst on-system contingency. 
None of the previously mentioned organizations has fully addressed voltage control in a restructured, competitive generation market. California's efforts at restructuring have extended, or at least made more explicit, the relationships among the various parties when providing reactive-power management (Pacific Gas and Electric et al. 1997). California will have an ISO that will be charged with the planning and operating responsibilities associated with maintaining reliability and facilitating markets. One of these responsibilities involves assuring the adequacy and reliability of voltage support. But the California ISO has no generation resources of its own (it is independent of all generation). The ISO obtains reactivepower-generation resources by making them a condition of connection to the grid. All generators are required to have a continuous operating range from 0.90 power factor lag (producing VARs) to 0.95 power factor lead (absorbing VARs). The ISO has the right to direct generators to operate anywhere within this range. The generator receives no compensation for this operation. Only if the ISO requires a generator to operate outside this range will the ISO compensate the generator.

\section{REQUIREMENTS IN A RESTRUCTURED INDUSTRY}

ISO management of reactive resources involves equipment capability and actual delivery. That is, the ISO must acquire (by either mandate or purchase) the right to specified amounts of reactive-power capability. That power must then be delivered (or absorbed) in response to the time-varying and location-specific requirements of the system.

The system operator uses analysis tools to help determine what voltage-control resources are needed and, to a lesser extent, how to deploy those resources most efficiently. A constrained optimal-power-flow analysis can determine the reactive-power dispatch that minimizes realpower losses or calculate location-specific reactive-power prices (El-Keib and Ma 1997). Including physical limits, bus voltage requirements, and contingencies as constraining conditions assures that the calculated solutions meet the physical requirements. If all costs are presented to the system operator, the optimal power flow can be used to find a least-cost solution.

Application of alternative objective functions can lead to very different uses of reactivepower devices. According to one analysis, traditional VAR dispatch seeks to minimize control actions (Dandachi et al. 1996). Minimizing the cost of voltage control could lower voltagesupport costs by about one fourth. The resulting solution, however, leads to an entirely different voltage profile that requires many more control actions, such as adjustments of transformer taps.

In a competitive environment, determination of who has provided what service will be more important. Use of claimed capability may not be adequate. The actual VAR output from a generator may not match the manufacturer's capability specifications. Public Service Company of Colorado found that operating limits often prevent generators from providing full rated VAR output. Adjustment of tap settings on the step-up (and other) transformers, adjustment of station service voltage levels, and recalibrating and setting alarms and meters (and sometimes replacing meters) are often needed to increase the actual VAR output. Better 
training of operators on the use of voltage-control equipment is also important. This utility achieved a 500-MVAR increase in actual capability at 13 generating units, a 50\% increase in output (Panvini and Yohn 1995).

Because actual and predicted performance might not match well, ECAR (1996) developed methods for rating the real- and reactive-power performance of generating units under normal operating conditions. The reactive-power tests must be conducted at least once every two years and require maintenance of scheduled voltages for at least two hours. ISOs will likely develop and implement similar methods to be sure that the reactive supplies contracted to the ISO can and do perform as specified. A corresponding set of penalties must also be developed to deter persistent noncompliance.

ISOs can acquire reactive resources either through mandates or purchases. The California ISO (as noted above) chose the mandatory approach. Other ISOs plan to pay generators their embedded costs for reactive resources. To the extent that reactive supplies are not geographically restricted, it might be possible to create competitive markets for the acquisition of such resources. Many believe that the location limitations on reactive resources are sufficiently great that competitive markets cannot develop for this service. Unfortunately, determining the embedded cost of generator-provided reactive power is ambiguous at best. This ambiguity occurs because the same equipment is used to provide both real and reactive power. What percentages, for example, of the exciter, generator stator, generator rotor, turbine assembly, and stepup transformer should be assigned to each function?

A Southern Company proceeding before FERC illustrates well these complexities. Southern proposed to assign some of the cost of the turbines and 100\% of the costs of the exciter and its cooling system to reactive power. FERC (1997b) disagreed and assigned 100\% of the turbine cost to real-power production. Southern computed its reactive-power charges on the basis of a pair of load-flow studies, a base case and a transaction case. Southern used the difference in reactive-power requirements between the two cases as the basis for its proposed charges. FERC rejected the use of incremental pricing for generator reactive power because Southern was using embedded-cost pricing for transmission-supplied reactive power.

Finally, the ISOs and the other participants in bulk-power markets will need to decide which entity has the responsibility and authority to plan for and determine the need for (and location of) additional reactive resources and how those resources are to be used. Some utilities rely primarily on transmission equipment to maintain voltages under normal operating conditions; these utilities use their generator reactive capabilities only to respond to contingencies (Nedwick, Mistr, and Croasdale 1995). Other utilities rely on their generators to manage voltages under normal operating conditions. Who, in the future, will make these kinds of decisions? 


\section{CONCLUSIONS}

The process of controlling voltages and managing reactive power on interconnected transmission systems is well understood from a technical perspective. Three objectives dominate reactive-power management. First, maintain adequate voltages throughout the transmission system under current and contingency conditions. Second, minimize congestion of real-power flows. Third, minimize real-power losses.

This process must be performed centrally because it requires a comprehensive view of the power system to assure that control is coordinated. System operators and planners use sophisticated computer models to design and operate the power system reliably and economically. Various devices can be deployed to control voltages with varying capital and operating costs, varying degrees of control, and varying performance characteristics.

Far less effort has been directed at finding commercially efficient ways of providing the resources needed for voltage control. Central control by rule works well but may not be the most economically effective means. The economic impact of control actions can be quite different in a restructured industry than for vertically integrated utilities. While it may be sufficient to measure only the response of the system in aggregate for a vertically integrated utility, determining individual generator performance will be critical in a competitive environment.

FERC elected to separate generation- and transmission-based voltage control, making the former an ancillary service while leaving the latter embedded in the basic transmission service. FERC also recognized that reactive power cannot be transported as far as real power, making it unclear if there will be enough generators available in the right locations to create competitive markets for reactive power.

FERC made a reasonable start, but much more needs to be done. Generator opportunity costs should be addressed. On the other hand, a fixed capability requirement like that established in California makes little sense. While it reduces or eliminates opportunity costs by providing sufficient capacity, it can waste capital. When an investor is considering construction of new generation, the amount of reactive capability that the generator can provide without curtailing real-power production should depend on system requirements and the economics of alternatives, not on a fixed rule. The introduction of advanced devices, such as STATCOMs and SVCs, further complicates the split between transmission- and generation-based voltage control. The fast response of these devices often allows them to substitute for generation-based 
voltage control. But their high capital costs limit their use. If these devices could participate in a competitive voltage-control market, efficient investment would be encouraged.

In areas with high concentrations of generation, sufficient interaction among generators is likely to allow operation of a competitive market. In other locations, introduction of a small amount of controllable reactive support on the transmission system might enable market provision of the bulk of the reactive support. In other locations, existing generation would be able to exercise market power and would continue to require economic regulation for this service. A determination of the extent of each type within each region would be a useful contribution to restructuring.

NERC (1997) emphasized the importance of planning and operating systems to maintain voltages as the U.S. electricity industry is restructured:

System planners and operators need to work closely together during the design of new facilities and modification of existing facilities. Planners must design adequate reactive support into the system to provide satisfactory voltage profiles during normal and contingency operating conditions. Of particular importance is sufficient dynamic support, such as the reactive output of generators, which can supply additional reactive power during contingencies. System operators must have sufficient metering and analytical tools to be able to tell when and if the operational reactive resources are sufficient. Operators must remain cognizant of any equipment outages or problems that could reduce the system's static or dynamic reactive support below desirable levels.

Ensuring that sufficient reactive resources are available to control voltages may be increasingly difficult because of the deintegration of the electricity industry. Traditional vertically integrated utilities contained, within the same entity, generator reactive resources, transmission reactive resources, and the control center that determined what resources were needed when. In the future, these resources and functions may be placed within three different entities. In addition, these entities will have different, perhaps conflicting, goals. In particular, the owners of generating resources will be driven, in competitive generation markets, to maximize the earnings from their resources. They will not be willing to sacrifice revenues from the sale of real power to produce reactive power unless appropriately compensated. Similarly, transmission owners will want to be sure that any costs they incur to expand the reactive capabilities on their system (e.g., additional capacitors) will be reflected fully in the transmission rates that they are allowed to charge. Thus, although reactive-power costs are only about $\$ 1.5$ billion today (Kirby and Hirst 1996), failure to appropriately compensate those entities that provide voltage-control services could lead to serious reliability problems and severe constraints on commercial transactions. 


\section{ACKNOWLEDGMENTS}

We thank Steve Purucker and Westinghouse for the information and comments they provided. We thank Robert Lux, Steve Purucker, Jess Totten, Raymond Vice, Bruce Walkup, and Stephen Whitley for their very helpful comments on a draft of this report. We thank Fred O'Hara for editing the report; and we thank Ethel Schorn for managing the clearance, publication, and distribution process. 



\section{REFERENCES}

F. L. Alvarado 1996, Methods for the Quantification of Ancillary Services in Electric Power Systems, draft, University of Wisconsin, Madison, WI, February.

N. H. Dandachi, M. J. Rawlins, O. Alsac, M. Prais, and B. Stott 1996, "OPF for Reactive Pricing Studies on the NGC System," IEEE Transactions on Power Systems 11(1), 226-232, February.

M. W. Davis 1994, "Testimony," before the Michigan Public Service Commission, Case Nos. U-10143 and U-10176, Detroit Edison, Detroit, MI, August 26.

East Central Area Reliability Coordination Agreement 1996, ECAR Document No. 4, Criteria and Methods for the Uniform Rating of Generation Equipment, Canton, OH, August.

East Central Area Reliability Coordination Agreement 1997, ECAR/MAAC/SERC Tri-Regional Assessment Reliability Impact of the Delayed Completion of the Wyoming-Cloverdale 765-kV Line, draft, Canton, OH, January.

Electric Reliability Council of Texas 1997, ERCOT Operating Guides, Austin, TX, October.

A. A. El-Keib and X. Ma 1997, "Calculating Short-Run Marginal Costs of Active and Reactive Power Production," IEEE Transactions on Power Systems 12 (2), 559-565, May.

Florida Reliability Coordinating Council 1996, FRCC Planning Principles and Guides, Principles and Guides for Planning Reliable Bulk Electric Systems, Tampa, FL, September.

E. Hirst and B. Kirby 1997, Creating Competitive Markets for Ancillary Services, ORNL/CON448, Oak Ridge National Laboratory, Oak Ridge, TN, October.

J. P. Kessinger 1997, "Flexible AC Transmission Systems," presented to DOE Task Force on Electric-System Reliability, Plymouth, MA, September 24.

B. Kirby and E. Hirst 1996, Ancillary-Service Costs for 12 U.S. Electric Utilities, ORNL/CON427, Oak Ridge National Laboratory, Oak Ridge, TN, March.

P. Nedwick; A. F. Mistr, Jr.; and E. B. Croasdale 1995, "Reactive Management: A Key to Survival in the 1990s," IEEE Transactions on Power Systems 10(2), 1036-1043, May. 
New England Power Pool 1996, Attachment B to Restated NEPOOL Agreement, NEPOOL Open Access Transmission Tariff, Holyoke, MA, December.

North American Electric Reliability Council 1996, Policy 2, Transmission Operations \& Voltage and Reactive Control, Princeton, NJ, October.

North American Electric Reliability Council 1997, Reliability Assessment 1997-2006, Princeton, NJ, October.

Northeast Power Coordinating Council 1992, Guidelines for Inter-Area Voltage Control, NPCC Operating Procedure Coordinating Committee and NPCC System Design Coordinating Committee, New York, NY, December.

Northeast Power Coordinating Council 1996, Memorandum of Agreement, New York, NY, November.

Pacific Gas and Electric, San Diego Gas \& Electric, and Southern California Edison 1997, The Phase II Filing of the California Independent System Operator Corporation and The Phase II Filing of the California Power Exchange Corporation, Docket Nos. EC96-19-001 and ER961663-001, before the Federal Energy Regulatory Commission, San Francisco, San Diego, and Rosemead, CA, March 31.

A. Panvini and T. J. Yohn 1995, "Field Assessment of Generator Reactive Capability," IEEE Transactions on Power Systems 10(1), 288-296, February.

PJM Interconnection, LLC 1997a, Dispatching Operations Manual M-12, Revision 01, Norristown, PA, July.

PJM Interconnection, LLC 1997b, Transmission Operations Manual M-03, Revision 01, Norristown, PA, June.

S. Purucker 1997, personal communication, Westinghouse, Orlando, FL, August.

H. Rustebakke 1983, Electric Utility Systems and Practices, $4^{\text {th }}$ edition, John Wiley \& Sons, New York, NY.

Southeastern Electric Reliability Council 1995, Principles and Guides for Reliability in System Planning, Birmingham, AL, April.

Southwest Power Pool 1997, Southwest Power Pool Independent System Operator Proposal, Little Rock, AR, March. 
U.S. Federal Energy Regulatory Commission 1996, Promoting Wholesale Competition Through Open Access Non-Discriminatory Transmission Services by Public Utilities; Recovery of Stranded Costs by Public Utilities and Transmitting Utilities, Final Rule, Docket Nos. RM95-8000 and RM94-7-001, Order No. 888, Washington, DC, April 24.

U.S. Federal Energy Regulatory Commission 1997a, Promoting Wholesale Competition Through Open Access Non-discriminatory Transmission Services by Public Utilities; Recovery of Stranded Costs by Public Utilities and Transmitting Utilities, Order on Rehearing, Docket Nos. RM95-8-001 and RM94-7-002, Order No. 888-A, Washington, DC, March 4.

U.S. Federal Energy Regulatory Commission 1997b, Opinion and Order Affirming in Part and Reversing in Part Initial Decision, Opinion No. 416, Docket Nos. ER91-150-000 et al., Washington, DC, September 16. 



\section{REACTIVE-POWER BASICS}

To understand reactive power and the relationship between power factor and voltage control, one must understand alternating current (AC). The voltage and current produced by a generator oscillate 60 times a second with the shape of a sine wave. The sine wave is the natural motion of a rotating circle and is produced because generators rotate at constant speed.

Power $(\mathrm{P})$ is the product of voltage $(\mathrm{V})$ and current $(\mathrm{I}): \mathrm{P}=\mathrm{V} \times \mathrm{I}$. Figure 7 shows that this product is always positive if the voltage and current oscillate together, even though both the voltage and the current are negative half the time. The power pulsates for a single phase (one set of voltage and current). Power systems use three phases offset by 120 degrees from each other (delayed by one-third of a cycle) so that the total power from all three phases is constant.

If the current wave is delayed slightly from the voltage wave, the two are no longer in phase, and the current is said to lag the voltage. The resulting power is sometimes positive (the generator is delivering power to the load) and sometimes negative (the generator is taking power from the load ). In this case, energy is transferred from the generator to the load, and the magnitude of that energy transfer oscillates 120 times a second between the generator and the load. If the current lags the voltage by 90 degrees, the power oscillates but no net energy transfer from the generator to the load occurs (Fig. 8).

\section{INDUCTORS AND CAPACITORS}

Power oscillations between the generator and the load occur whenever the load is able to instantaneously store energy. Both inductors and capacitors store energy. Inductors store energy in a magnetic field, which results from the current flowing in the wire of the inductor. Capacitors store energy in an electrostatic field, which results from the voltage difference between the plates of the capacitor.

This storage of energy and oscillation of power can be explained by considering an inductor connected to an $\mathrm{AC}$ generator. When the generator voltage is at its maximum, current begins to build in the inductor (point A on Fig. 9), storing energy in the inductor's magnetic field. When the voltage reverses (point B), the current is still flowing in the inductor in the positive direction because energy has built up in the inductor's magnetic field. The energy flows out of the inductor and into the generator because of the negative generator voltage and the positive inductor current. As the magnetic field in the inductor collapses, energy leaves the 


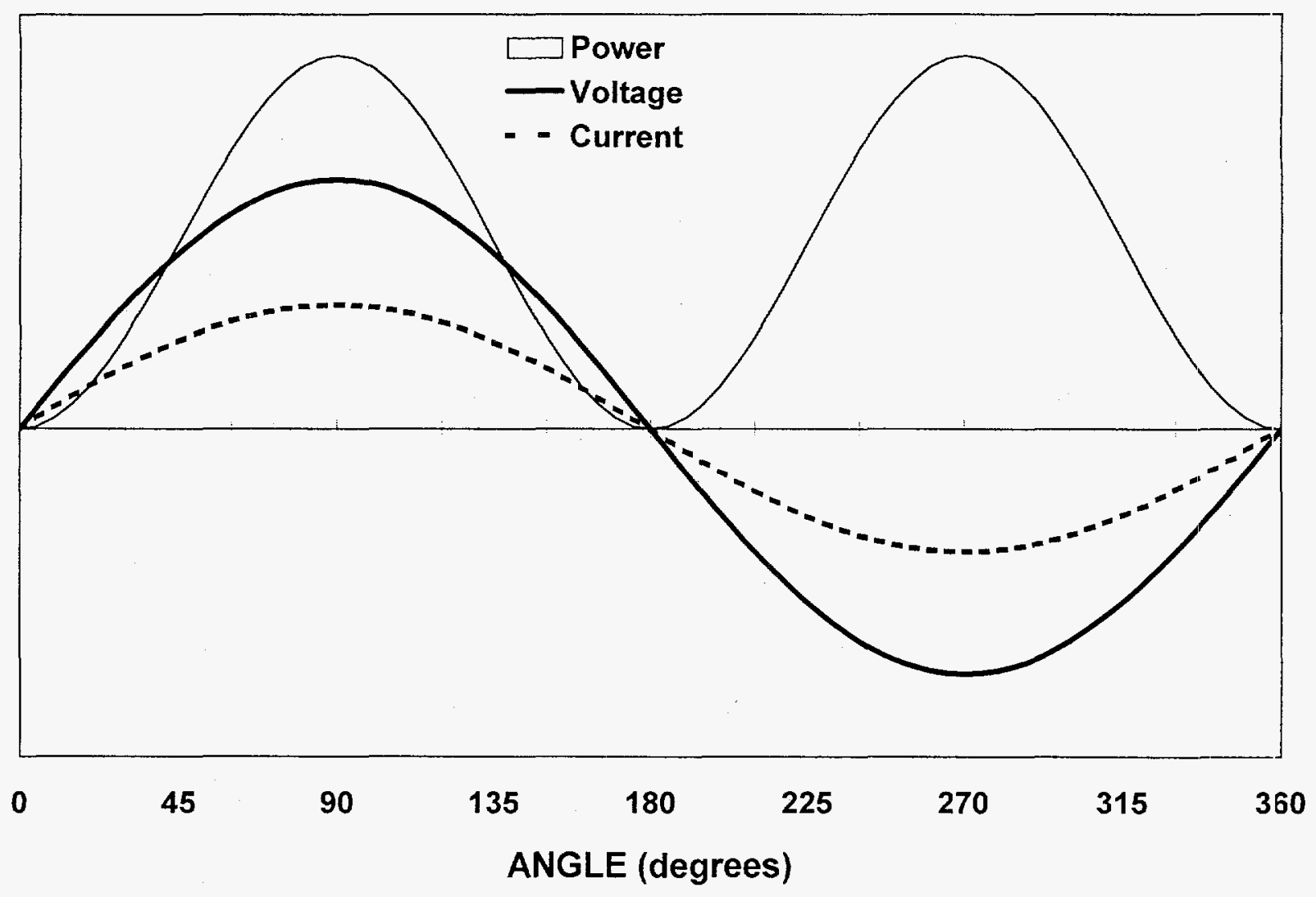

Fig. 7. Relationships among current, voltage, and real-power output.

inductor, and the current drops. Once the energy, magnetic field, and current drop to zero (point $\mathrm{C}$ ), the current and magnetic field start building in the opposite direction, driven by the generator's negative voltage. Power flows from the generator to the inductor again because both the voltage and the current are negative, storing energy in the inductor. This lasts only as long as the voltage remains negative. When the generator reverses voltage again (point $D$ ), the positive generator voltage and negative inductor current send power from the inductor to the generator, reducing the stored energy in the inductor. At point $\mathrm{E}$, the generator voltage has again reached a maximum, and the process repeats itself.

Capacitors behave the same way, except that the current leads the voltage by 90 degrees, and the energy is stored in the electrostatic field (depending on voltage). The power flows between the $\mathrm{AC}$ generator and the capacitor are opposite from the power flows between the generator and the inductor. That is, when power is flowing from the generator to the inductor (between points A and B in Fig. 9), power is flowing from the capacitor to the generator. When the energy stored in the inductor is at its lowest (points A, C, and E in Fig. 9), the energy stored in the capacitor is at its highest. 


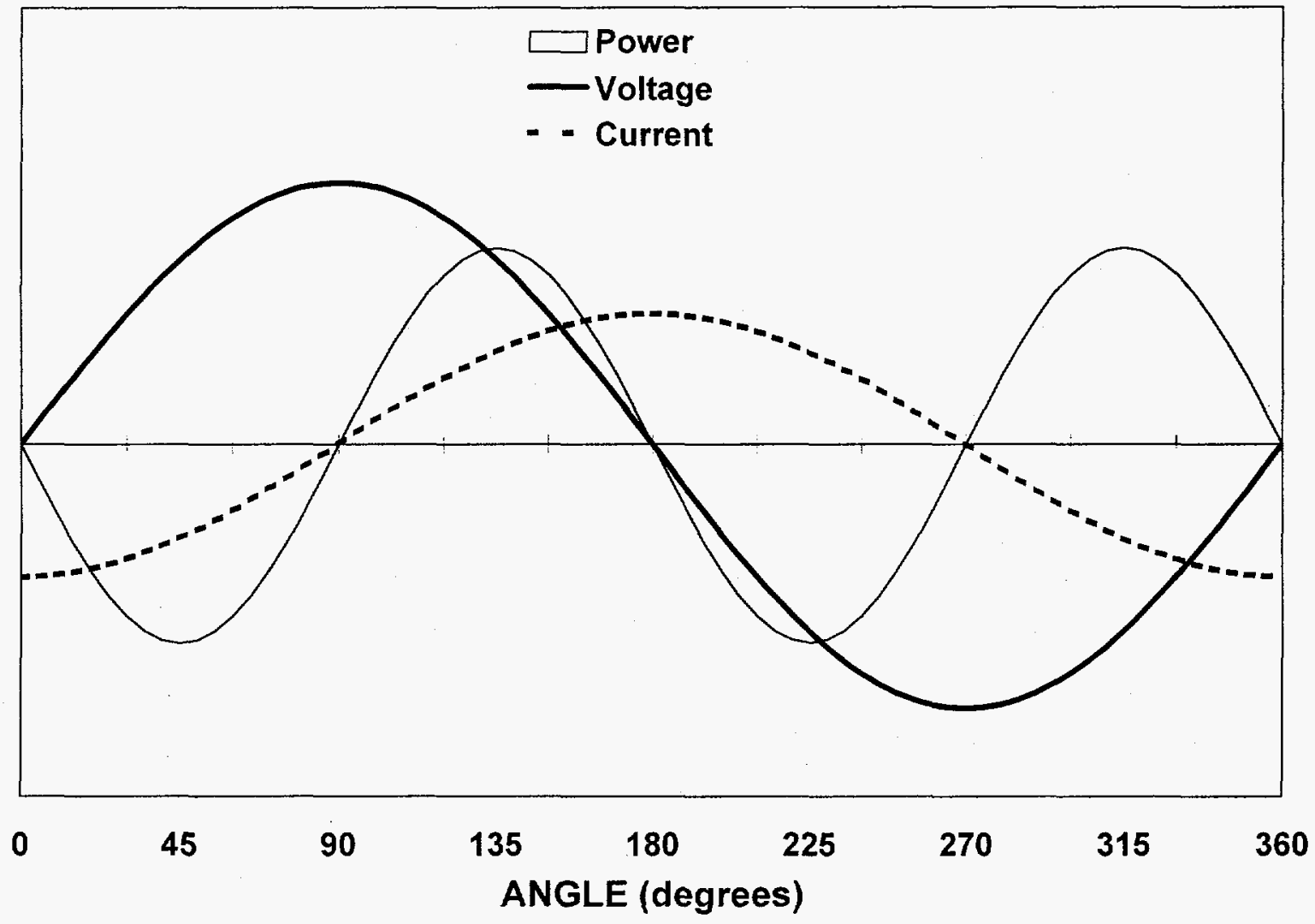

Fig. 8. Relationships among voltage and lagging current and resultant power output. (With current lagging voltage by $90^{\circ}$, no net power is transferred.)

This phenomenon is important because nearly all power-system components have capacitance and/or inductance associated with them. ${ }^{*}$ In fact, inductance is the dominant characteristic of most power-system components (e.g., generators, overhead lines, transformers, and motors). Underground cables and, to a lesser extent, overhead lines have significant capacitance, as well. Consequently, these oscillations occur all the time.

\section{POWER FACTOR}

The current associated with transferring energy back and forth between the $\mathrm{AC}$ generator and the inductor or capacitor does not deliver useful energy to the load. The concept of power factor was developed to express how much of the total current supports the transfer of useful energy to the load (real power) and how much supports oscillations (reactive power). Because reactive power results from current that is out of phase with voltage by 90 degrees

"Capacitance is the characteristic of certain electrical equipment that leads to the production of reactive power in $\mathrm{AC}$ systems. Inductance (also called reactance) is the characteristic that leads to the absorption of reactive power. Both characteristics are functions of the materials used to make the pieces of equipment and the spatial relationships (geometry) among these elements. 


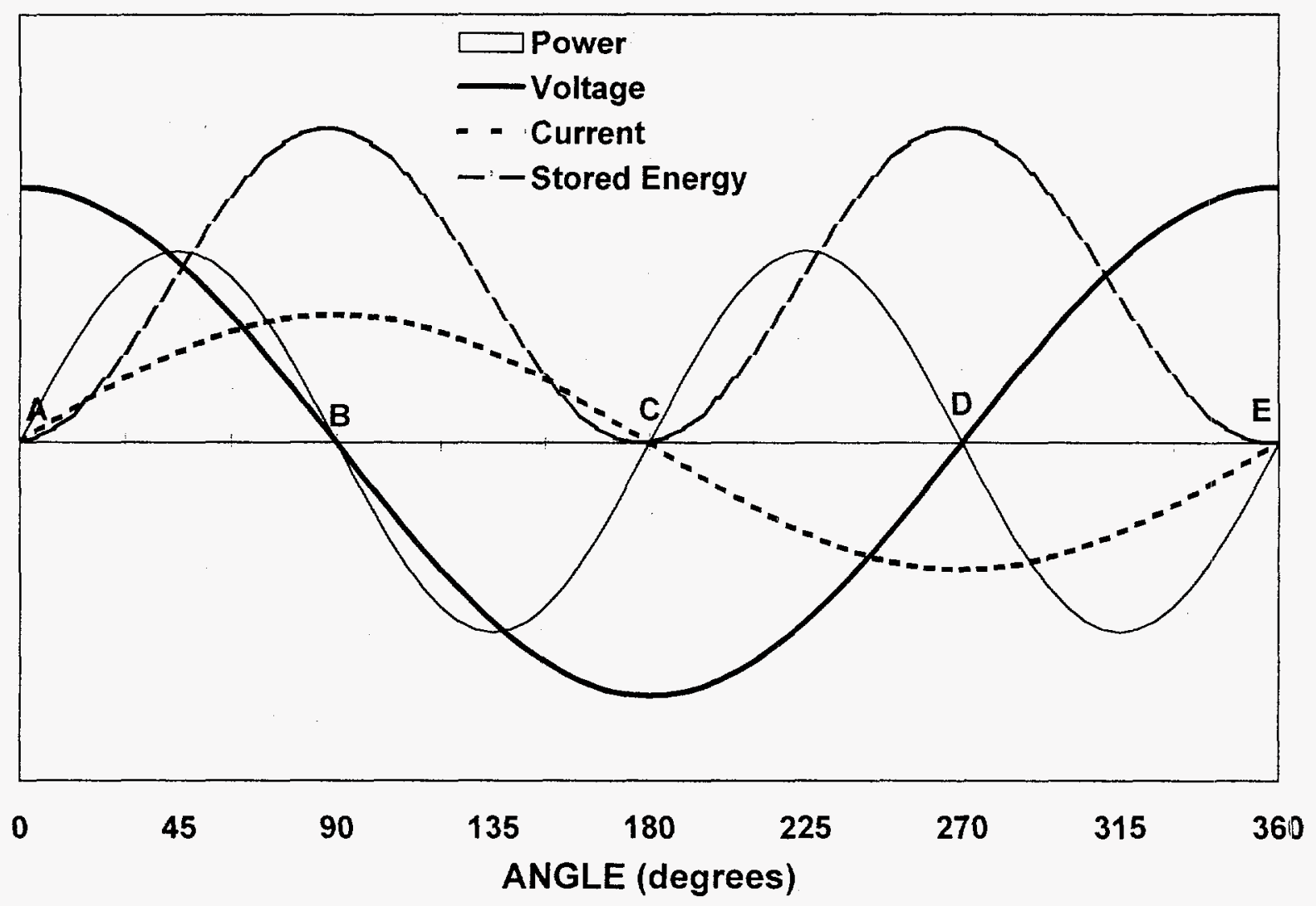

Fig. 9. Power transfer and energy oscillations in the presence of an inductor,

(either lagging because of inductance or leading because of capacitance) and real power results from current that is in phase with voltage, the two add geometrically to form apparent power. The power factor is defined as the ratio of real power to apparent power. Real power is measured in watts (W), reactive power is measured in volt-amps reactive (VAR), and apparent power is measured in volt-amps (VA).

Transmission-system components, such as transmission lines and transformers, have to carry the total current or the apparent power. Load losses (e.g., the losses associated with the resistance* of transmission lines) also result from the total current. The lower the power factor and the greater the reactive load, the higher the losses.

Most transmission-system equipment is limited in the amount of current it can carry because high currents passing through the small resistance of the equipment generate heat that must be removed." So, a poor power factor lowers the capacity of the transmission system to

*Resistance is the property of electrical equipment that results in the conversion (loss) of electrical energy to thermal energy when an electrical current passes through the equipment.

"For overhead transmission lines, the current creates heat, which expands and weakens the conductor. The thermal limit of the line is reached when the line either sags too low to be safe or weakens and pulls 
move useful energy to the load by consuming some of the limited current-carrying capacity with reactive current.

Because inductive current lags voltage and capacitive current leads voltage, the two can be used to cancel each other. If a load is inductive (as nearly all loads are because of motors, flourescent light ballasts, transformers, etc.), it can be compensated for with capacitors so the total load presented to the power system has a power factor of $100 \%$ (or any other desired value). Most industrial and many commercial power contracts require the customer to maintain a power factor above some minimum level (often 95\%). Customers can install capacitors to adjust their power factor if it is below this limit.

\section{VOLTAGE DROP}

Voltage drop results from the interaction of the current being carried with the impedance (resistance, capacitance, and inductance) of the transmission line or transformer. Current (i) passing through a resistor (R) produces voltage drop $(\Delta \mathrm{V}): \Delta \mathrm{V}=\mathrm{I} \times \mathrm{R}$. If the load is real ( $100 \%$ power factor), the voltage at the load plus the resistive voltage drop in the transmission lines equals the generator voltage. If the transmission-line impedance is inductive rather than resistive, the voltage drop across the inductor is rotated 90 degrees from the load current. The line voltage drop is the same magnitude as in the resistive case, but because it is not aligned with the supply voltage, the resulting load voltage is higher than in the resistive case (although it now lags the supply voltage). If the load current is inductive itself and therefore lags the supply voltage by 90 degrees, the resulting voltage drop in the inductive line is once again aligned with but opposite to the supply voltage. So inductive loads supplied through inductive lines have higher voltage drops than do real loads supplied through inductive lines (Fig. 10).

Overhead lines and transformers have series inductive reactances that are on the order of 10 times their series real impedances (i.e., the inductance is 10 times the resistance). This difference occurs because resistance is related to the properties of the conductor and the amount of it that is used, while the inductance and capacitance are related to the geometry of how the equipment is constructed. Conductors are made from copper or aluminum because these materials have low resistance and not from steel (except to carry weight) because it has higher resistance. Resistance can be further reduced by using a bigger conductor. For an overhead transmission line, the inductance depends on the conductors themselves. The dominant factor is the spacing among the conductors, with higher inductance resulting from greater spacing. Large spacing is required, however, to insulate high-voltage conductors from each other. Because of this spacing, the reactive load (lower power factor) interacts with the higher inductive impedance to produce most of the voltage drop seen throughout the power system.

apart. For transformers, the current heats transformer mass and eventually damages the insulation. In both cases, the thermal time constants of the equipment, the amount of the overload, and the ambient temperature determine how long the overload can be tolerated. 

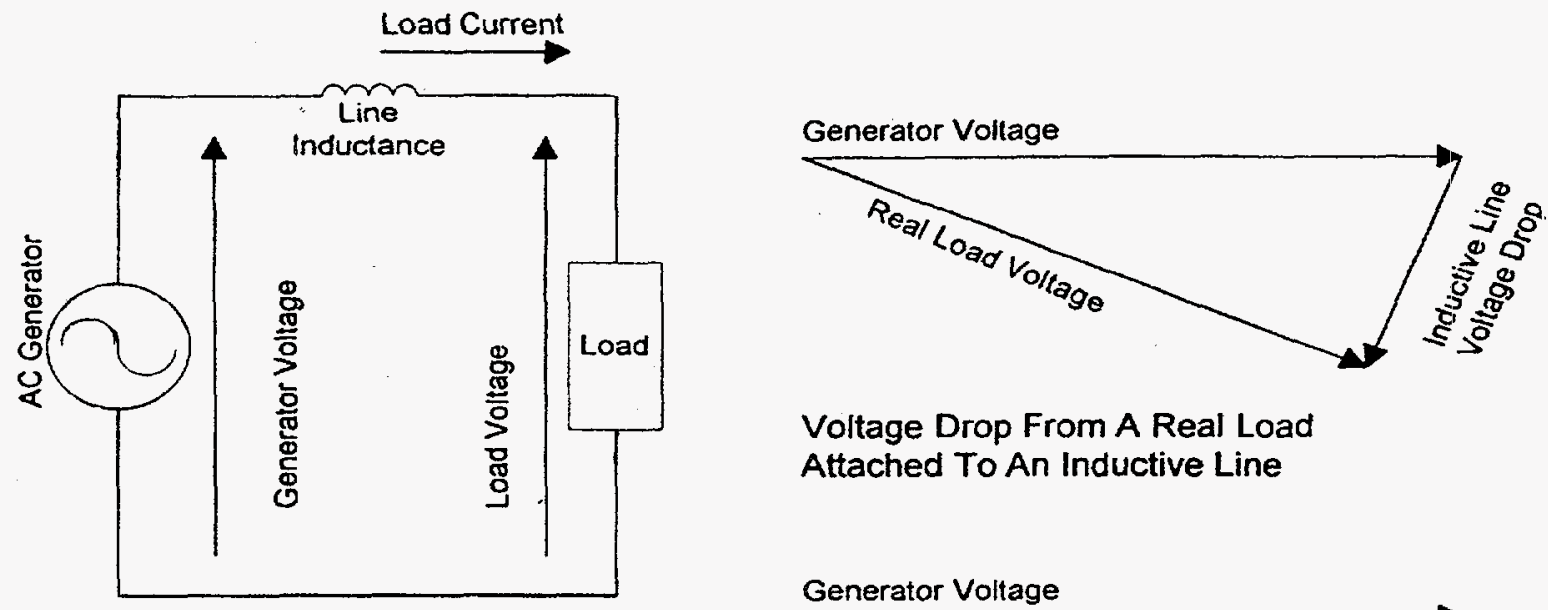

Voltage Drop From A Real Load

Attached To An Inductive Line

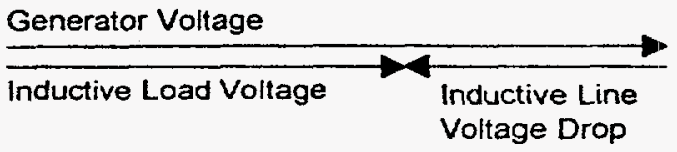

Voltage Drop From An Inductive Load Attached To An Inductive Line

Fig. 10. Voltage drop caused by a real load and an inductive load supplied through an inductive line. 


\section{INTERNAL DISTRIBUTION}

1. V. D. Baxter

2. L. Berry

3. D. J. Bjornstad

4. M. A. Brown

5. J. Christian

6. G. Courville

7. T. R. Curlee

8. P. D. Fairchild

9. S. Hadley

10. L. J. Hill

11. E. Hirst

12. P. J. Hughes

13. B. Kirby

14. R. Lee
15. P. Leiby

16. J. M. MacDonald

17. V. C. Mei

18. D. E. Reichle

19. A. C. Schaffhauser

20. M. Schweitzer

21. R. B. Shelton

22. J. Tomlinson

23. B. E. Tonn

24. J. Van Dyke

25. J. VanCoevering

26. T. J. Wilbanks

27. Central Research Office

28. Document Reference Section

29. Laboratory Records (RC)

\section{EXTERNAL DISTRIBUTION}

30 .

31.

32.

33.

34.

35.

$36 .-37$

38 .

39. -750
Dr. Lilia A. Abron, President, PEER Consultants, P.C., 1000 N. Ashley Drive, Suite 312 , Tampa, FL 33602

Dr. Thomas E. Drabek, Professor, Department of Sociology, University of Denver, Denver, CO 80208-0209

Dr. Stephen G. Hildebrand, Director, Environmental Sciences Division, Oak Ridge National Laboratory, P.O. Box 2008, Oak Ridge, TN 37831-6037

Mr. P. Richard Rittelmann, FAIA, Executive Vice President, Burt Hill Kosar Rittelmann Associates, 400 Morgan Center, Butler, PA 16001-5977

Dr. Susan F. Tierney, The Economic Resource Group, Inc., One Mifflin Place, Cambridge, MA 02138

Dr. C. Michael Walton, Ernest H. Cockrell Centennial Chair in Engineering and Chairman, Department of Civil Engineering, University of Texas at Austin, Austin, TX 78712-1076 OSTI, U.S. Department of Energy, P.O. Box 62, Oak Ridge, TN 37831

Office of Assistant Manager for Energy Research and Development, DOE/ORO, P.O. Box 2001, Oak Ridge, TN 37831-8600

External Electric Industry Policy Studies group distribution mailing list and extra copies to

E. M. Schorn, 4500N, H-19A 